\title{
Estrogenic influences in pain processing
}

Asa Amandusson and Anders Blomqvist

\section{Linköping University Post Print}

\section{Tweet}

N.B.: When citing this work, cite the original article.

Original Publication:

Asa Amandusson and Anders Blomqvist, Estrogenic influences in pain processing, 2013, Frontiers in neuroendocrinology (Print), (34), 4, 329-349.

http://dx.doi.org/10.1016/j.yfrne.2013.06.001

Copyright: Elsevier

http://www.elsevier.com/

Postprint available at: Linköping University Electronic Press

http://urn.kb.se/resolve?urn=urn:nbn:se:liu:diva-100488 


\title{
Estrogenic Influences in Pain Processing
}

\author{
Åsa Amandusson ${ }^{\mathrm{a}}$ and Anders Blomqvist ${ }^{\mathrm{b}}$
}

a Department of Clinical Neurophysiology, Uppsala University, 75185 Uppsala, Sweden, and ${ }^{b}$ Department of Clinical and Experimental Medicine, Division of Cell Biology, Faculty of Health Sciences, Linköping University, 58185 Linköping, Sweden.

Correspondence to: Dr. Åsa Amandusson, E-mail: asa.amandusson@akademiska.se, or Dr. Anders Blomqvist, E-mail: anders.blomqvist@liu.se 


\begin{abstract}
Gonadal hormones not only play a pivotal role in reproductive behavior and sexual differentiation, they also contribute to thermoregulation, feeding, memory, neuronal survival, and the perception of somatosensory stimuli. Numerous studies on both animals and human subjects have also demonstrated the potential effects of gonadal hormones, such as estrogens, on pain transmission. These effects most likely involve multiple neuroanatomical circuits as well as diverse neurochemical systems and they therefore need to be evaluated specifically to determine the localization and intrinsic characteristics of the neurons engaged. The aim of this review is to summarize the morphological as well as biochemical evidence in support for gonadal hormone modulation of nociceptive processing, with particular focus on estrogens and spinal cord mechanisms.
\end{abstract}

Key words: Nociception; Gonadal hormones; Estrogens; Estrogen receptors; Spinal dorsal horn; Medullary dorsal horn; Steroid hormones; Enkephalin; Opioid; Pain mechanisms 


\section{Introduction}

Estrogens have an extraordinarily wide range of actions in the human body. Not only do they exert profound effects on sexual differentiation and behavior, but they also modulate cardiovascular function, bone formation, hemostasis, water and salt balance, and metabolic rate. The existence of an ovarian hormone was suggested already in the $19^{\text {th }}$ century but it was not until 1923 that Allen and Doisy discovered and extracted an ovarian estrogenic hormone (Allen and Doisy, 1923). Since that time, countless experiments within the field of hormonal research have shown that estrogens, originally considered to be purely female gonadal hormones, actually have a fundamental role in basic cellular mechanisms in both males and females.

The brain is one of the major targets of estrogen action. Recent studies have documented the complexity and detail of estrogen function in the central nervous system, and they have shown just how extensive is the impact of estrogens on many of the cardinal brain systems. This review is concerned with the effects of estrogens on one of these systems - the nociceptive system - with a specific emphasis on pain-modulating effects in the spinal cord and lower brain stem. These effects have been known for a long time but progress within the field in the past few years has added critically important morphological and molecular detail, making it possible to examine this pain-modulating effect at the cellular as well as structural level.

Before further discussing the effects of estrogens on pain transmission, as well as the potential clinical significance of these effects, an overview of the mechanisms of estrogen action and of the basic structure of the nociceptive system will be given as a background.

\section{Mechanisms of action of estrogens in the central nervous system}

\subsection{The synthesis of estrogens}

\subsubsection{Systemic synthesis of estrogens}

Estrogens belong to the steroid hormone family and are thus based on cholesterol. Via a number of intermediate steps, cholesterol is converted into pregnenolone from which all steroid hormones derive. Depending on which receptors and enzymes are present in the steroid-producing cells, different hormones (e.g. aldosterone, cortisone, estradiol, testosterone) are produced (see e.g. Ghayee and Auchus, 2007).

The precursors of estrogens are androstenedione and testosterone, which are converted to estrone and estradiol by aromatization catalyzed by the P450 aromatase monooxygenase enzyme complex (Fig 1). The primary source of $17 \beta$-estradiol, the most potent and biologically active of the estrogens, is the ovaries but aromatase is also found in fat, muscle, testes and brain. The biologically weaker estrogens estriol and estrone are mainly formed in the liver from estradiol and in the placenta.

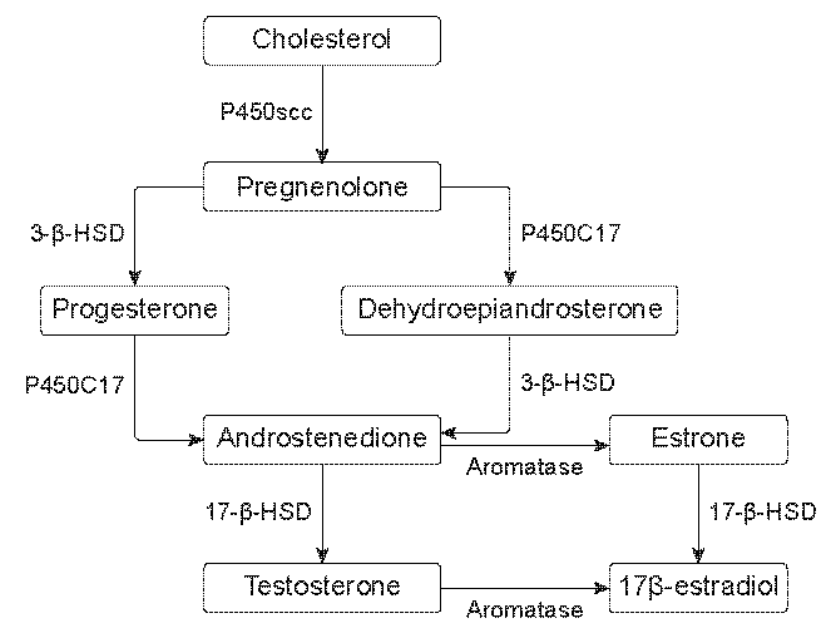

Figure 1. Synthesis of estrogens. All enzymes required to convert cholesterol to estrogens have been found in brain tissue (for details see section 2.1). 3- $\beta$ HSD, 3- $\beta$-hydroxysteroid dehydrogenase; $17 \beta$-HSD, $17 \beta$-hydroxysteroid dehydrogenase. 
The secretion of estrogens is regulated by bursts of gonadotropin-releasing hormone $(\mathrm{GnRH})$ from the hypothalamus that in turn induce the release of FSH and LH from the pituitary. When the stimulating hormones reach steroid-producing cells, they immediately induce mobilization of cholesterol thus initiating steroid synthesis. The regulation is complex, including both negative and positive feedback-loops since hormone levels change continuously during the menstrual cycle; this regulatory process will not be described in detail here.

\subsubsection{Local synthesis of estrogens in the brain}

All the enzymes needed to convert cholesterol to estrogens have been found in brain tissue (Micevych and Mermelstein, 2008), implying that the brain can work as an autonomic steroidogenic organ. Certain brain areas, such as the rat hippocampus, may produce estrogens de novo from cholesterol (Prange-Kiel and Rune, 2006). In addition, testosterone and androstenedione, present in both the female and the male of most species, freely enter the brain where they may be converted by the enzyme aromatase into estradiol and estrone, respectively (Cornil et al., 2006). Aromatase is present in presynaptic terminals in many brain regions (Evrard et al., 2000; Naftolin et al., 1996) suggesting that estrogens can become available locally where they can act in a paracrine manner (Cornil et al., 2006; Evrard and Balthazart, 2004a). The rate of aromatization is lower in the brain than in other tissues but may be modified locally by estrogens and androgens as well as by different neural stimuli (Evrard and Balthazart, 2003). Endogenous changes in glutamate and dopamine transmission may inactivate production very quickly (Baillien and Balthazart, 1997; Cornil et al., 2006). Thus, in the brain, rapidly changing levels of locally produced estrogens may instantly affect neuronal function. This immediate and transient production of estrogens thus adds another time range to the one supplied by systemic estrogens changing slowly with the estrous cycle (Hojo et al., 2008), making it possible for estrogen to instantly cause effects in specific regions.

The brain is a tissue rich in lipids and may as such serve as a reservoir of the fat-soluble estrogens that may be slowly released thereafter. The actual concentration of estrogens in certain areas of the brain is therefore not known but it has been suggested that local estradiol concentrations in the hypothalamus are higher than in the circulation (Bixo et al., 1997).

\subsection{By which cellular mechanisms do estrogens exert their effects?}

Estrogens are lipid-soluble and freely enter the cells by simple diffusion. A discussion of the complexity of the many different cellular pathways and transcriptional mechanisms affected by estrogens in general is beyond the scope of this review so these mechanisms are only summarized briefly here (for further detail, see e.g. Heldring et al., 2007; Malyala et al., 2005; McEwen et al., 2012; Tetel and Pfaff, 2010).

\subsubsection{Estrogen receptors}

Before 1960, it was believed that estrogens exerted their actions mainly by taking part in enzymatic processes (Jensen and Jordan, 2003). Jensen and Jacobsen then showed, however, that some tissues could accumulate radioactive estradiol against a concentration gradient, indicating the presence of an intracellular hormone-binding protein (Jensen and Jacobsen, 1962). They were able, along with other research groups (Toft and Gorski, 1966), to attribute this effect to the presence of the estrogen receptor (ER), a steroid receptor belonging to the nuclear receptor superfamily. The estrogen receptor is made up of functionally distinct domains. Among these are the DNA-binding domain, which is able to recognize and bind to specific DNA sequences and is also able to induce dimerization, the ligand-binding domain, and the NH2-terminal domain, which is involved in facilitation of transcriptional activation. 
When the ER is not bound to its ligand, it is located in the nucleus or cytoplasm and is stabilized by a complex of heat-shock proteins that mask the ligand- and/or DNA-binding region of the receptor. Estrogens passively diffuse into the cell and bind to the ligand-binding domain, which in turn is altered thereafter leading to the dissociation of heat-shock proteins and subsequent binding to motor proteins such as dynein allowing for further transport to the nucleus. In the nucleus, the ER binds to specific sequences of DNA called estrogen-response elements (ERE) (Fig 2). The consensus ERE (5'GGTCAnnnTGACC3') (Klein-Hitpass et al., 1986) is only found in a few estrogen-inducible genes such as Efp (estrogen-responsive finger protein; involved in cell proliferation) and COX7RP (cytochrome c oxidase subunit VIIrelated protein) (O'Lone et al., 2004). For other genes, e.g. transforming growth factor $\alpha$, glial fibrillary acidic protein, oxytocin, angiotensinogen, and progesterone receptor, variants of the consensus ERE or partial EREs have been described. There are approximately 70,000 EREs in the human genome, of which 5,000-10,000 have been considered potentially functional (Dietz and Carroll, 2008).

As a result of binding to DNA, the ER modifies the chromatin structure opening up its architecture thereby stimulating the assembly of the transcriptional machinery needed for transcription. The ER can then activate gene transcription, ultimately leading to increased synthesis of the proteins encoded by these genes (Fig 2). On termination of transcription, the estrogen dissociates from the receptor, which is then detached from the DNA, complexed with heat-shock proteins, and finally rendered inactive. The ER thus acts as a transcription factor whose activity is modulated by co-activators and co-repressors. The conformation of the ER depends on the ligand and on the ERE, which results in differential recruitment of coregulators (Gruber et al., 2004; Shiau et al., 1998). The end result is to restrict the specific hormonal response to the cells that express the appropriate set of co-regulators and other transcription factors. The different co-regulators may also act in competition with other hormone receptors. A high degree of functional cellular specificity may result, even if the estrogens are lipid-soluble and therefore reach most cells of the body.

The ERs may also activate transcription independent of EREs by interfering with the activity of other transcription factors (Fig 2). For example, ER $\alpha$ activates AP-1 dependent transcription by stabilizing the binding of Fos and Jun to the AP-1 site (Gaub et al., 1990; Uht et al., 1997) rather than binding directly to DNA. Genes encoding collagenase and insulin-like growth factor are known to be regulated by estrogens in this way (Gruber et al., 2004). The estrogen responsiveness of the genes encoding retinoic acid receptor- $\alpha$ and c-myc is due to the interaction of the ERs with yet another transcription factor, Sp-1. In common with most nuclear receptors, the ER is a phosphoprotein and its function may thus also be altered by phosphorylation, even in the absence of a ligand. The receptor may thereby be activated by protein kinases independently of estrogen. Ligand-independent activation of ERs has been shown in vitro for dopamine, epidermal growth factor, transforming growth factor $\alpha$, and cyclic AMP (Gruber et al., 2002).

Thus far, two subtypes of the ER have been described, ER $\alpha$ (ESR1) cloned in 1985 (Walter et al., 1985) and ER $\beta$ (ESR2) cloned 10 years later (Kuiper et al., 1996; Mosselman et al., 1996). The receptors are highly homologous in the DNA-binding domain (97\%) but are otherwise rather dissimilar and coded from genes located on two different chromosomes. The ligand-binding domains share a 55\% sequence homology, resulting in lower affinities for endogenous $17 \alpha$ - and $17 \beta$-estradiol to ER $\beta$ than ER $\alpha$, whereas the reverse is true for phytoestrogens, for example (Kuiper et al., 1997). The two subtypes have somewhat different distributions in the body, and they have opposing effects in some respects in spite of the homology of the DNA-binding domain, due to the recruitment of different subsets of coregulators and somewhat different distribution within the cell. In some tissues (such as thyroid, uterus and brain) both receptors are co-expressed and form functional heterodimers 
(Matthews and Gustafsson, 2003). When co-expressed, ER $\beta$ often inhibits ER $\alpha$-mediated gene expression and often opposes the actions of ER $\alpha$ (Heldring et al., 2007).

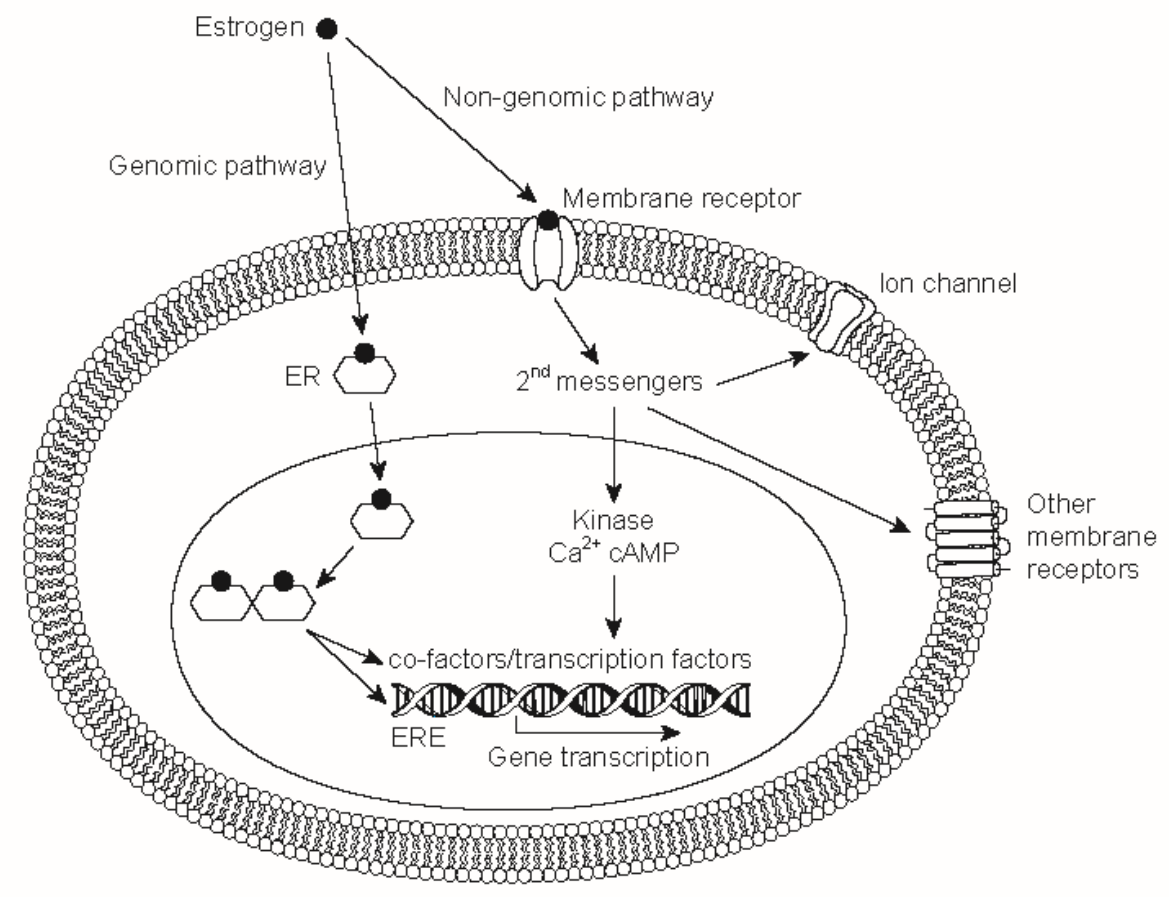

Figure 2. Cellular mechanisms of estrogens in summary. Estrogen freely passes through the cell membrane and thereby has the potential to affect intracellular mechanisms and gene transcription by many different pathways. Two different ways of action have been studied in particular. The genomic (classical) pathway involves estrogen receptors (ER) located in the cytoplasm and nucleus. Binding of estrogen to these receptors induces receptor dimerization and subsequent binding to estrogen responsive elements (ERE) and/or interaction with co-factors and other transcription factors thereby initiating gene transcription. The non-genomic (alternative, non-classical) pathway includes estrogenic action on membrane receptors, in turn activating intracellular pathways, ion channels and other membrane receptors. For details see section 2.2.

\subsubsection{Alternative (non-genomic, steroid-initiated) mechanisms of action}

The classic steroid signaling pathway, which involves nuclear interaction, proceeds at a rate such that it takes minutes to hours before an increase in protein synthesis can be observed. In contrast with this, it takes only a few seconds for estrogens to alter the electrical activity of preoptic neurons (Kelly et al., 1976) and to increase cAMP in the uterus (Szego and Davis, 1967), a time interval much too short for de novo protein synthesis such as that induced by direct ER-binding or activation of AP-1 dependent transcription. Estrogenic effects with very rapid onset are therefore considered to involve so-called non-classic/initially non-genomic pathways. These alternative mechanisms may involve estrogenic action on cell membranes, possibly mediated in part by membrane ERs (Fig 2). These membrane ERs may be novel or classical ERs associated with the plasma membrane. The presence of classic estrogen receptors may explain some of the non-genomic actions of estrogens (Abraham et al., 2004; Chaban and Micevych, 2005) but a brain-specific estrogen receptor X has also been proposed (Toran-Allerand et al., 2002). In addition, the G-protein-coupled receptor GPR30 may also bind estrogen (Revankar et al., 2005; Thomas et al., 2005). Several intracellular pathways such as the mitogen-activated protein (MAP) kinase pathway, the activation of transcription factors such as the cAMP response element-binding protein (CREB), protein kinase $\mathrm{C}$ pathways, and direct modulation of $\mathrm{Ca}^{2+-}$ channels (McEwen, 2001), are all affected by estrogens and affect, in turn, the estrogen receptors. High concentrations of estradiol are often needed to elicit these alternative mechanisms of action. As noted above, locally high concentrations of estrogens can arise as a result of the synthesis of estrogens at specific 
locations in the brain. This enables the activation of non-genomic responses regionally, thereby avoiding the need for high estrogen concentrations systemically, concentrations that could cause severe adverse effects on non-neural tissue (Cornil et al., 2006). The regulation of lordosis behavior (Micevych and Mermelstein, 2008) and signaling in the dorsal root ganglion (Chaban and Micevych, 2005) are in the time range more compatible with non-classic mechanisms (Micevych and Dominguez, 2009).

The actions of estrogens are thus determined by the structure and synthesis of the ligand, the subtype of the estrogen receptor, the co-regulators and transcription factors involved and the characteristics of the target gene itself. Moreover, the substantial cross talk that takes place between pathways as well as different aspects of epigenetic modification of chromatin adds further complexity. This combination of factors provides a broad spectrum of potential pathways to be employed by estrogen-responsive cells in a tissue- and subpopulation-specific manner, triggering in turn multiple patterns of responses that regulate gene expression, cytoplasmic signaling pathways, membrane receptors, and ion channels.

\subsection{Estrogen receptors in the central nervous system}

Even though estrogens may act through mechanisms not requiring ERs, the ERs undoubtedly form the basis of estrogen action and localizing these receptors in varying tissues has therefore been seen as the key to understanding estrogenic effects.

The distribution of ERs in different regions of the brain was first shown in studies using autoradiographic techniques (Keefer et al., 1973; Pfaff and Keiner, 1973; Pfaff, 1968; Stumpf and Sar, 1976). Subsequent anatomical studies using immunohistochemistry and in-situ hybridization confirmed these results and added greater detail. In the rodent, ERs are found in neurons as well as in glial cells (Jung-Testas et al., 1992) and neural stem cells (Brannvall et al., 2002). ER $\alpha$ predominates in the ventromedial hypothalamus but is more or less absent in the cortex and cerebellum, whereas ER $\beta$ is present in the cortex and cerebellum in addition to other regions, such as the preoptic area, amygdala, thalamus and some nuclei in the brain stem (Shughrue et al., 1997; Shughrue and Merchenthaler, 2001). In certain areas, such as the preoptic area, ER $\alpha$ and ER $\beta$ are co-expressed (Shughrue et al., 1998).

The amount of ERs varies during the estrous cycle in a region-specific pattern. In the preoptic area, for example, the amount of ER mRNA is low during periods of high estrogen levels whereas the opposite is true in the arcuate nucleus (Shughrue et al., 1992). Considering the many signaling pathways modulated by estrogens and the large number of brain cells that are responsive to estrogens, it is not surprising that estrogens have profound effects on both the development of the morphological structure of the brain (organizational effects) and on temporary physiological events (activational effects). Studies of ER knockout mice have shown that the individual survives without one or the other ER - or even both (Walker and Korach, 2004), but its reproductive functions deteriorate, suggesting that estrogens are not essential to life as such but are indispensable to the survival of mammalian species.

The key role of estrogens in placentalia postnatally is estrus induction, the initiation of ovulation (Lange et al., 2002). For this reason, the reproductive role of estrogens has traditionally been the major focus of hormonal research. In the late 1980s, however, several studies indicated other non-reproductive effects (McEwen et al., 2012; Woolley and McEwen, 1992). One major such effect not directly coupled to reproductive function is the ability of estrogens to influence neuronal migration and survival. ER $\beta$-knockout mice exhibit prominent morphological abnormalities with severe neuronal deficiency and disorganization in the cerebral cortex (Wang et al., 2003). By regulating anti-apoptotic genes, estrogens act in a neuroprotective way in response to ischemic damage, for example. Estrogens also stimulate dendritic outgrowth and synaptic remodeling in, for example, the hippocampus (Gould et al., 1990; Woolley and McEwen, 1992). Furthermore, estrogens may act as vasodilators and 
increase blood perfusion of the brain (Wise et al., 2001) and they have significant regulatory effects on most neurotransmitter systems (McEwen, 2001; McEwen et al., 2012). Through modulation of these systems, estrogens influence many basic body functions, ranging from the regulation of appetite, food and water ingestion, thermoregulation and weight gain to effects on motivation, mood and aggressive behavior.

In addition, estrogens regulate processing in somatosensory systems. In rats, estrogen treatment has been shown to significantly enlarge the receptive field of sensory nerves $(22 \%$ larger than controls for the pudendal nerve (Kow and Pfaff, 1973) and a stunning $840 \%$ for the trigeminal nerve (Bereiter and Barker, 1975)). Sex differences in various parameters of vision, auditory sensitivity and olfaction have also been reported (Gandelman, 1983; Hultcrantz et al., 2006). Even though the sex differences in these latter examples are not necessarily controlled by estrogens only, the accumulated effects of estrogens on the different somatosensory systems are striking. This review deals primarily with the possible effects of estrogens on yet another sensory signaling from the body, the signaling of pain. Before elaborating further on the potential modulatory effects of estrogens on pain transmission, the basic features of the nociceptive system will be reviewed.

\section{The nociceptive system}

\subsection{Introduction}

According to the International Association for the Study of Pain, pain may be defined as "an unpleasant sensory and emotional experience associated with actual or potential damage, or described in terms of such damage" (IASP Task Force on Taxonomy, iasp-pain.org). A welladjusted system for transmitting pain is absolutely essential if we are to maintain the integrity of our body. Traditionally, two major views on pain processing exist in the scientific community. One states that pain is processed by specific pathways ("labeled lines") made up of distinct sets of neurons peripherally as well as centrally, whereas the other claims that pain is not signaled by a specific system of neurons as such but instead by activation in multimodal neurons that also react to other sensory stimuli (for reviews, see Craig, 2003a; Perl, 2011).

During the past years an increasing amount of evidence has accumulated that demonstrates the presence of a specific pathway dedicated to pain. It has become clear that the concept that the pain system is part of the somatosensory system, a view still often found in medical textbooks, is in need of revision. Recent advances in cellular and molecular science have shown that if gene expression and regulation, intracellular mechanisms, and anatomical and physiological characteristics are taken into account in characterizing the nociceptive system, then this system is homologous with the different interoceptive, homeostatic systems to a greater degree than it is with the classic exteroceptive somatosensory systems (Craig, 2002, 2003b). The interoceptive homeostatic systems such as those that monitor body status through temperature regulation, visceral sensations, hunger, thirst, respiration and itch, strive to maintain an optimally balanced state for the organism. The notion that pain processing forms part of this homeostatic network is in many ways a conceptual shift, which, in turn, implies a close connection between the nociceptive system and the autonomic nervous system, the hypothalamic-pituitary-adrenal-axis, and other neuroendocrine systems. This view may also explain the different aspects of pain dealt with in the clinical setting and opens up the possible need to consider that certain pain conditions depend on homeostatic dysfunction rather than on actual tissue damage. The association of nociceptive pathways with the interoceptive homeostatic system is further indicated by the anatomical characteristics and biochemical features of the nociceptive system, which will be described below. 


\subsection{Structural components in nociceptive processing via the spinal cord}

Nociceptors are receptors that respond selectively to stimuli that cause, or threaten to cause, tissue damage. The nociceptors are located on free nerve endings of either thinly myelinated axons $(\mathrm{A} \delta)$ or unmyelinated axons $(\mathrm{C})$. Contrary to what is indicated by their name, most of the surface of these endings is actually covered by Schwann cells and only parts of the endings are exposed. Different receptor molecules serve to detect different signals such as noxious heat, lowered $\mathrm{pH}$, strong mechanical stimuli, and hypoxia (Cortright et al., 2007; Weidner et al., 1999). Due to their different morphology, the A $\delta$ - and C-fibers have different latencies and conduction velocities. A $\delta$-fiber activity gives rise to the early sharp feeling of pain, whereas C-fiber activity usually gives rise to the later, duller pain sensation. The cell bodies of these axons are in the dorsal root ganglia (DRG), as are the somata of neurons responding to touch. The nociceptive afferents have small DRG cell bodies. There are two subsets of small DRG neurons, one that contains TrkA (the nerve growth factorreceptor), calcitonin gene-related peptide, and substance $\mathrm{P}$, and a second one that is identified by isolectin B4-binding. The thin postganglionic afferent fibers enter laterally into the ipsilateral dorsal horn of the spinal cord. The afferent input to the dorsal horn is organized modality-wise so that nociceptive afferents mainly terminate in Rexed's lamina I and II (with a lesser afferent component in lamina $\mathrm{V}$ and $\mathrm{X}$ ), whereas innocuous sensory information mainly terminates in laminae III-V (Christensen and Perl, 1970; Sugiura et al., 1986). The nociceptive $\mathrm{A} \delta$ - and $\mathrm{C}$-fiber afferents activate lamina I and II neurons with glutamate as the dominant transmitter (Fig. 3).

The majority of neurons ( $>95 \%)$ in the superficial dorsal horn are local circuit interneurons involved in the release of neuromodulatory substances such as enkephalin, glycin and GABA. These interneurons play a key role in the processing of nociceptive stimuli and in setting the overall "excitability level" in the spinal dorsal horn (Fields and Basbaum, 2005; Graham et al., 2007) (Fig. 3B). 

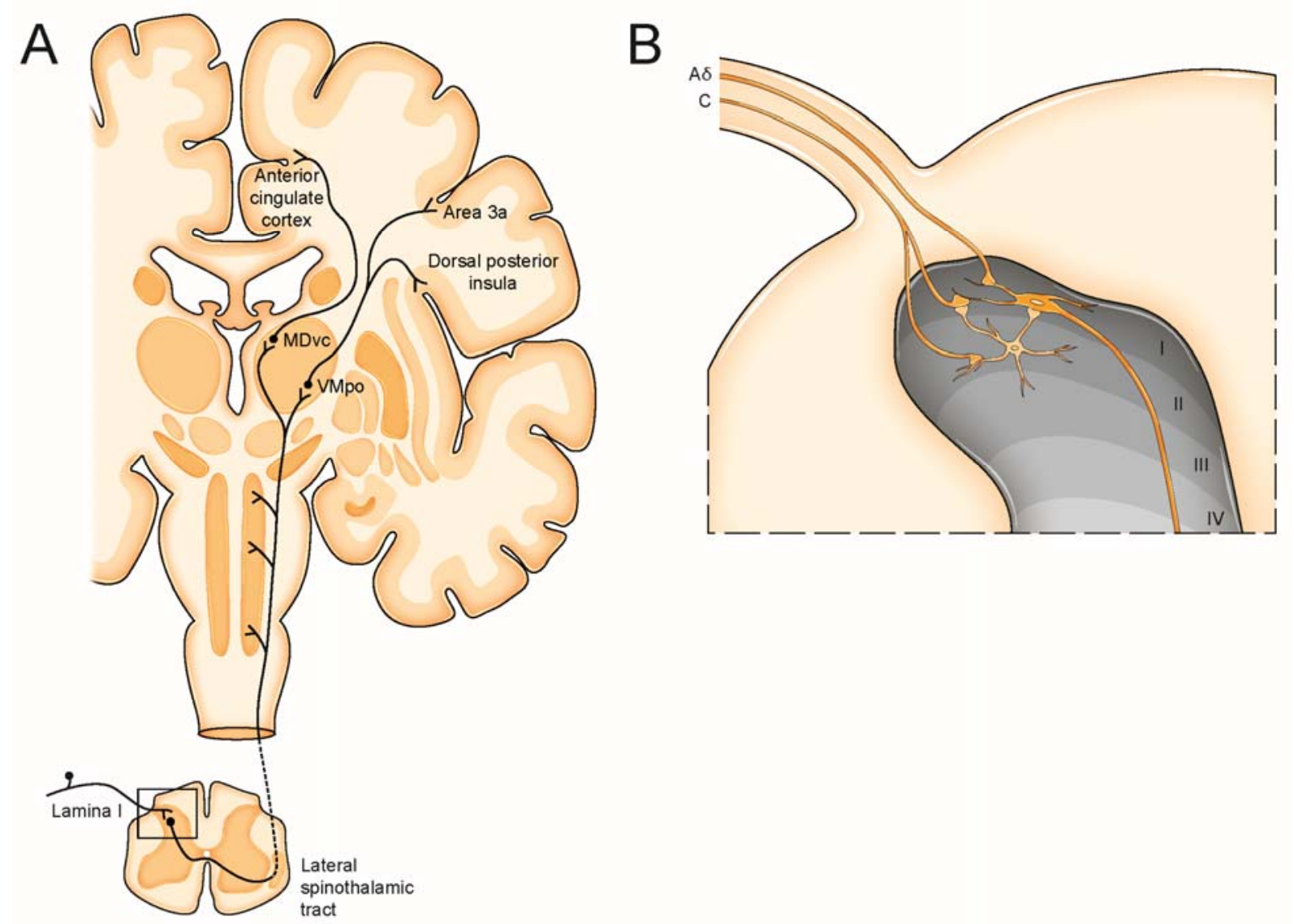

Figure 3. A. Ascending pain pathways. Schematic drawing of the spino-thalamo-cortical system. MDvc, ventral caudal portion of the medial dorsal nucleus; VMpo, posterior part of the ventral medial nucleus. B. The dorsal horn of the spinal cord (insert in A.). Schematic overview of nociceptive afferent input to the superficial laminae. Peripheral A $\delta$-fibers terminate mainly in lamina I with some projections also to lamina $\mathrm{V}$ and $\mathrm{X}$ (not shown) and C-fibers end in lamina I and II. In lamina II, interneurons containing enkephalin and other neuropeptides may affect primary afferent nociceptive transmission pre- or postsynaptically. Adapted from Craig, $2003 \mathrm{a}$.

Approximately $30 \%$ of these neurons are inhibitory whereas the remainder is excitatory (Graham et al., 2007). These interneurons, which are preferentially located in lamina II, are under the control of powerful descending inhibitory or facilitating pathways with a supraspinal origin. Lamina II therefore has a unique strategically important role in the processing of primary afferent input before supraspinal transmission. Blocking of the inhibitory local interneurons in lamina II induces mechanical allodynia (i.e. an innocuous mechanical stimulus is perceived as painful) and hyperalgesia (i.e. a noxious stimulus elicits an increased painful sensation) (Campbell and Meyer, 2006).

The projection neurons are concentrated in lamina I although scattered projection neurons are seen in deeper laminae as well (Al-Khater et al., 2008). Nociceptive neurons in the superficial laminae project to the contralateral side directly at the spinal segmental level although some cells seem to project bilaterally (Spike et al., 2003). The neurons in lamina I have relatively small receptive fields and, at least in the cat and monkey, can be divided functionally as well as morphologically into three different classes. The first class, consisting of fusiform nociceptive-specific cells that have thin unmyelinated axons, mainly receive A $\delta$ fibers and are associated with first pain. The second class consists of pyramidal-shaped thermoreceptive-specific cells that have myelinated axons and respond to innocuous cooling, and the third class consists of multipolar multimodal cells that have myelinated axons and respond to heat, pinching and cooling (Christensen and Perl, 1970; Craig et al., 2001). The 
lamina I projection neurons send their axons to distinct thalamic nuclei (see below), which in turn project to distinct cortical areas (Craig, 2002). The majority of lamina I neurons also projects to the parabrachial nucleus in the brain stem, an integrative center for homeostatic afferent activity, and other neurons project to the periaqueductal gray matter, thoracolumbar sympathetic nuclei and the catecholamine groups A1-2 and A5-7 located in the brain stem (Craig, 1995). Because lamina I thus contains modality-specific nociceptive and thermoreceptive neurons it has been proposed that "the fundamental role of lamina I neurons is to distribute modality-selective sensory information on the physiological status of the tissues of the entire mammalian body to both sensory and homeostatic substrates" (Han et al., 1998). Understanding the functioning of lamina I is thereby crucial to the above mentioned idea of pain as a homeostatic component, something which is also reflected in its embryologic origin where it, contrary to the rest of the dorsal horn, arises from progenitors of autonomic interneurons in the lateral horn which migrated to the superficial laminae (Altman and Bayer, 1984).

In primates at least, the lamina I spinothalamic neurons projects to a nociceptive specific relay nucleus, the posterior part of the ventral medial nucleus, VMpo (Craig et al., 1994). The VMpo in turn projects to a part of the cortex often described as the interoceptive cortex, which is a part of the posterior insula, and, to a lesser extent, to the somatosensory cortex (Fig. 3A). Stimulation of the dorsal posterior insula in humans who are awake causes a distinct, well-localized pain (Mazzola et al., 2012; Ostrowsky et al., 2002) and in studies using functional neuroimaging, painful stimuli as well as noxious heat and cold activate this region (Craig, 2002, 2003b; Peyron et al., 2000). The same region is also activated during allodynia in patients with neuropathic pain or during itching, blood pressure manipulation, air hunger, hypoglycemia and thirst (for references, see Craig, 2002, 2003b), and lesions within this area reduce sensitivity to pain and temperature (Schmahmann and Leifer, 1992). This region also shares interconnections with the anterior cingulate, amygdala, hypothalamus and orbitofrontal cortex (Craig, 1995). The anterior parts of the anterior cingulate (aACC), which receives input from another terminal site of lamina I projection neurons, the ventrocaudal region of the mediodorsal nucleus (MDvc), have been shown to be of importance for the affective response to pain (anxiety, motivation, and volition) and the attentional reactions to pain (Treede et al., 1999). The aACC is also activated during placebo-induced analgesia (Colloca and Benedetti, 2005; Petrovic et al., 2002) and administration of opioids (Peyron et al., 2000). Nociceptive stimuli thus activate the interoceptive cortex as well as the anterior cingulate thereby inducing both sensation and motivation. This spino-thalamo-cortical pain pathway is only seen in primates; subprimate mammalian species exhibit a less specific and more integrated forebrain input, which suggests that they most likely do not experience pain in the same way as humans do (Craig, 2003b).

\subsection{Structural components in nociceptive processing via the trigeminal nucleus}

Whereas the spinal dorsal horn relays sensory input from the trunk and extremities, sensory information from craniofacial tissues is relayed by the trigeminal system. The three separate branches of the trigeminal nerve (ophthalmic, maxillary and mandibular) share a common ganglion, the trigeminal ganglion. Afferents from the trigeminal ganglion terminate in the trigeminal sensory nuclei, the nucleus of the solitary tract and in the dorsal horn of the upper cervical spinal segments (Pfaller and Arvidsson, 1988). The spinal trigeminal nucleus is further subdivided into oralis (Vo), interpolaris (Vi) and caudalis (Vc) divisions (Olszewski, 1950). The caudalis subdivision (Vc) merges caudally with the cervical dorsal horn and it is the principal brain stem relay site for nociceptive information from the face. The Vc has therefore been considered to be the brain stem equivalent to the spinal dorsal horn (Raboisson et al., 1995). Nociceptive afferents terminate mainly in lamina I and II of the dorsal parts of 
the Vc commonly referred to as the medullary dorsal horn. The trigeminal subnucleus caudalis and the spinal dorsal horn are not completely homologous although they have many features in common (for details, see Bereiter et al., 2000). Many neurons in the subnucleus caudalis are local interneurons or projection neurons intrinsic to the trigeminal complex. The extrinsic projection neurons project to the reticular formation, the parabrachial nucleus, cranial nerve motor nuclei and the thalamus.

\subsection{The endogenous opioid system}

Alongside the different ascending pathways involved in the transmission of nociceptive stimuli, there are several descending systems that reach the medullary and spinal dorsal horn (Willis, 1988). These descending systems adjust the excitability of the neurons involved in primary pain processing by acting both pre- and post-synaptically. Noradrenergic as well as serotonergic brain stem systems and input from the hypothalamus are examples of such descending systems. The most powerful descending pain-modulatory system, however, is the endogenous opioid system. Endogenous opioids have a wide array of effects but it is their massive pain-inhibitory capacity that has drawn the most attention as they may virtually abolish the feeling of pain in response to extraordinarily threatening situations, even though substantial tissue damage has been caused.

The endogenous opioids were one of the first class of neuropeptides to be discovered and identified (Hughes et al., 1975). Endogenous opioids are produced in the CNS, in the pituitary and adrenal glands. The opioid peptide family consists of both "typical" and "atypical" peptides. The typical peptides are derived from the precursor molecules proopiomelanocortin, pro-dynorphin and pro-enkephalin and share a common tetrapeptide sequence at their N-terminal, the domain primarily involved in signal transduction. The atypical opioid peptides, such as casomorphins and hemorphins, on the other hand, are derived from a variety of precursor proteins. The best-studied endogenous opioids in relation to pain transmission are enkephalin and dynorphin.

Enkephalin is derived from proenkephalin and exists in two different forms, metenkephalin and leu-enkephalin. Since each proenkephalin peptide contains four copies of metenkephalin but only one copy of leu-enkephalin, met-enkephalin is the most abundant (Hook et al., 2008). Proenkephalin is encoded by the preproenkephalin gene, which was first cloned in 1982 (Noda et al., 1982). Preproenkephalin mRNA, as well as its peptide product, is widely expressed in the brain (Harlan et al., 1987; Simantov et al., 1977). It is present in most laminae of the spinal cord with a concentration to the superficial laminae (Fig. 4C, D). In lamina I-II it is intimately connected to the modulation of nociception and $82 \%$ of the enkephalinergic neurons in these laminae express noxious-induced Fos (Noguchi et al., 1992). A variety of neuronal stimuli, such as seizures (Pennypacker et al., 1993), nociceptive stimuli (Draisci and Iadarola, 1989), and systemic immune challenge (Engstrom et al., 2003) induce preproenkephalin gene expression in a region-specific manner. In addition, hormones such as thyroid hormone and glucocorticoids may regulate the transcription of the preproenkephalin gene in the central nervous system (Ahima et al., 1992; Zhu et al., 1996). As will be described in more detail later, estrogens also have the ability to regulate enkephalin gene expression in certain brain regions (Priest et al., 1995; Romano et al., 1988).

Dynorphin, which is leu-enkephalin with carboxyl extensions of 12 amino acids, is derived from preprodynorphin, encoded by exon 4 of the preprodynorphin gene. Similar to preproenkephalin, the preprodynorphin gene was cloned in 1982 (Kakidani et al., 1982). The distribution of dynorphin largely follows that of enkephalins (Khachaturian et al., 1982; Weber et al., 1982), but while both are densely expressed in the superficial dorsal horn, they seem to constitute distinct populations (Marvizon et al., 2009). Dynorphin is both pro- and antinociceptive (Gintzler and Liu, 2012a). Dynorphin is released in the spinal cord upon 
peripheral tissue damage (Kajander et al., 1990; Malan et al., 2000), and intrathecal administration of dynorphin in animals has repeatedly been shown to induce pain (for refs. see Gintzler and Liu, 2012a). Furthermore, studies in dynorphin knock-out mice have demonstrated that dynorphin is necessary for the maintenance of sustained neuropathic pain (Wang et al., 2001). However, other studies, particularly those carried out by Alan Gintzler and collaborators have shown that under certain conditions, such as during pregnancy, dynorphin produces pain inhibition (for refs. see Gintzler and Liu, 2012a).
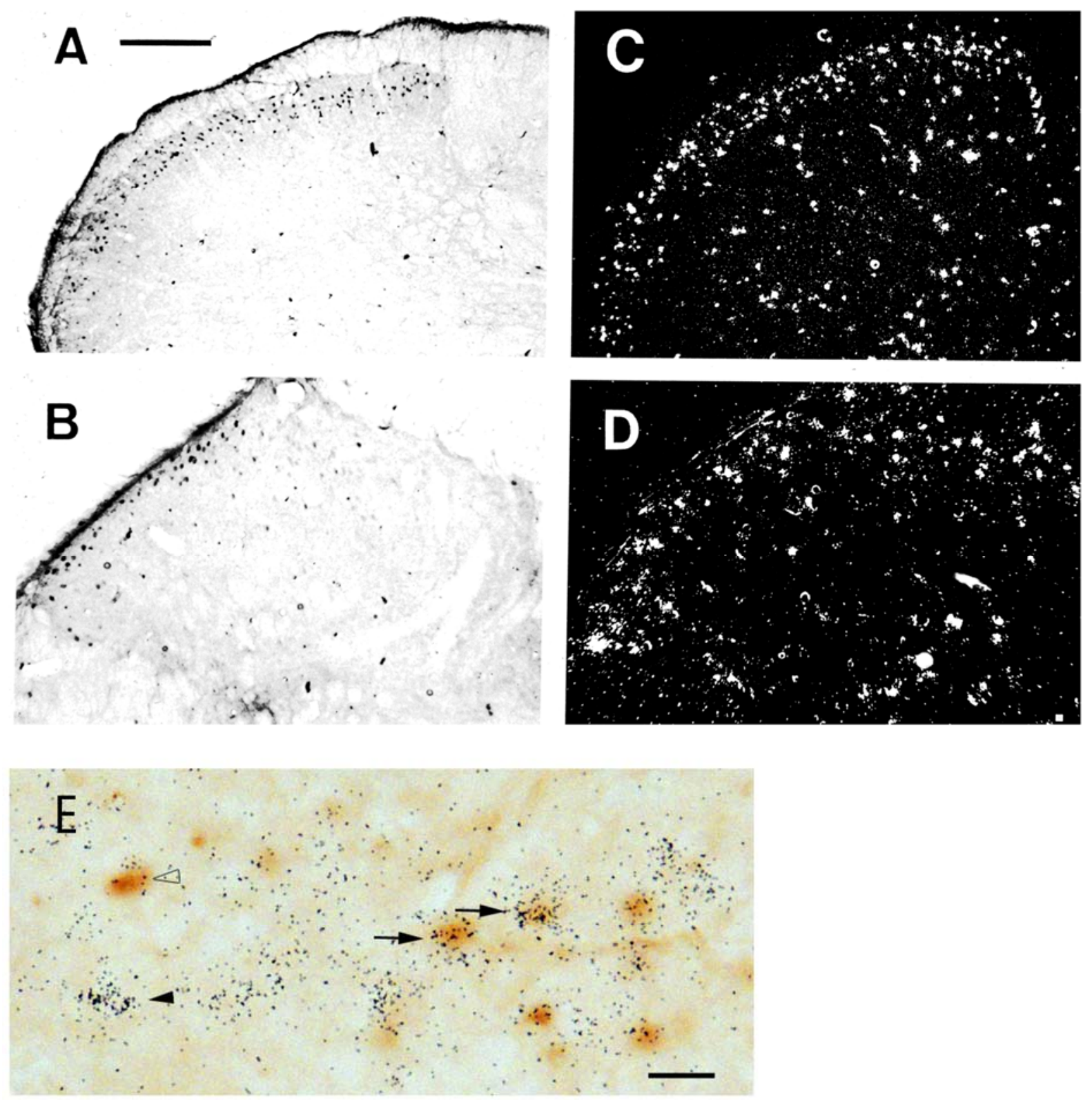

Figure 4. Distribution of estrogen receptor immunoreactivity (A, B) and preproenkephalin mRNA (the precursor mRNA of enkephalin) (C, D) in the medullary (top panel) and lumbar spinal (bottom panel) dorsal horn of the female rat. Note the overlapping labeling for the two markers in the superficial laminae. Reprinted from Amandusson et al. 1996. E, High-power micrograph showing cells double-labeled (filled arrows) for estrogen receptor immunoreactivity (brown) and preproenkephalin mRNA (black silver grains).Unfilled arrowhead points to a single-labeled estrogen receptor expressing neuron and the filled arrowhead points to a single-labeled preproenkephalin mRNA expression neuron. Scale bar $=250 \mu \mathrm{m}$ in A and C, $=100 \mu \mathrm{m}$ in B and D, and $20 \mu \mathrm{m}$ in $\mathrm{E}$. 
The opioids act primarily via opioid receptors (Lord et al., 1977) which are G-protein-coupled receptors that induce hyperpolarization of the neuron by affecting potassium conductance and voltage-gated calcium channels. These receptors were in fact detected before their endogenous opiate ligands were identified (Pert and Snyder, 1973; Terenius, 1973).

There are three well-defined receptor subtypes, $\delta$-, $\kappa$ - and $\mu$-receptors, which share many structural features but differ somewhat in the potency of their pain-inhibiting effects and addictive potential. The $\mu$-receptor is the most potent but is also the one most likely to induce dependence. In the spinal cord, $\delta$-, $\kappa-$, and $\mu$-opiate receptors are highly concentrated in the superficial laminae of the dorsal horn in the rat with only lower levels in the rest of the grey matter (Gouarderes et al., 1985). Enkephalin has the highest affinity with $\delta$-receptors but it also binds to $\mu$-receptors, albeit with a ten-fold lower affinity. Acute tissue damage induces a rapid increase in both preproenkephalin and preprodynorphin in the superficial laminae of the spinal cord (Draisci and Iadarola, 1989) where the increase in preproenkephalin is proportionally much smaller. On the other hand, the constitutive expression of preproenkephalin is higher suggesting a more constantly available pool of enkephalin in the spinal cord. Enkephalin decreases the responsiveness of nociceptive projection neurons through pre- and postsynaptic inhibition (Ma et al., 1997), and measures that increase enkephalin levels in the spinal cord induce antinociception and reduce pain (Wu et al., 1994). However, the opioid system also has a pivotal role in placebo analgesia (Colloca and Benedetti, 2005) where it has been shown that it is not only the primary pain-inhibiting mechanisms that result in pain relief but also the expectation of getting a pain killer, suggesting that the opioid system also acts at a cortical level to induce a mental "expectation pathway".

Apart from the effects on pain transmission, endogenous opioids also inhibit the release of LH and FSH and they may thereby prevent ovulation. Opioids also exert important effects on feeding, the regulation of body temperature, reward behavior, anxiety and the modulation of the immune response (Bodnar, 2008).

\section{The effects of female gonadal hormones on pain - general overview}

By viewing pain as a homeostatic emotion, the close interaction of pain pathways with other systems dedicated to the control and regulation of basal body functions has attracted great interest. As a result of this interest, a number of studies have focused on the potential effects of gonadal hormones on pain transmission (Fig. 5). These studies have mainly aimed at evaluating either sex differences in experiencing and responding to pain or the role played by different gonadal hormones in various (often behavioral) models of pain. Evaluating pain and pain-induced behavior in humans is much more complicated than evaluating pain in experimental animals since the outcome in humans is affected not only by the modality and location of the stimulus but also by medication, social environment, age, coping, attention, expectation, and mood state (Greenspan et al., 2007). Furthermore, studies on human subjects often involve only a small number of subjects in each study, making the drawing of conclusions even more difficult. In what follows, animal studies are reviewed first followed by a review of human studies. Since the aim of this review is to focus on the underlying mechanisms of hormonal effects on nociceptive processing rather than on the relationships between sex, gender and pain, this overview covers only a sample of the many studies in the field. Excellent reviews of sex differences in response to clinical and experimental pain are available and can provide additional detail (e.g., Berkley, 1997; Fillingim et al., 2009; Racine et al., 2012; Wiesenfeld-Hallin, 2005). 


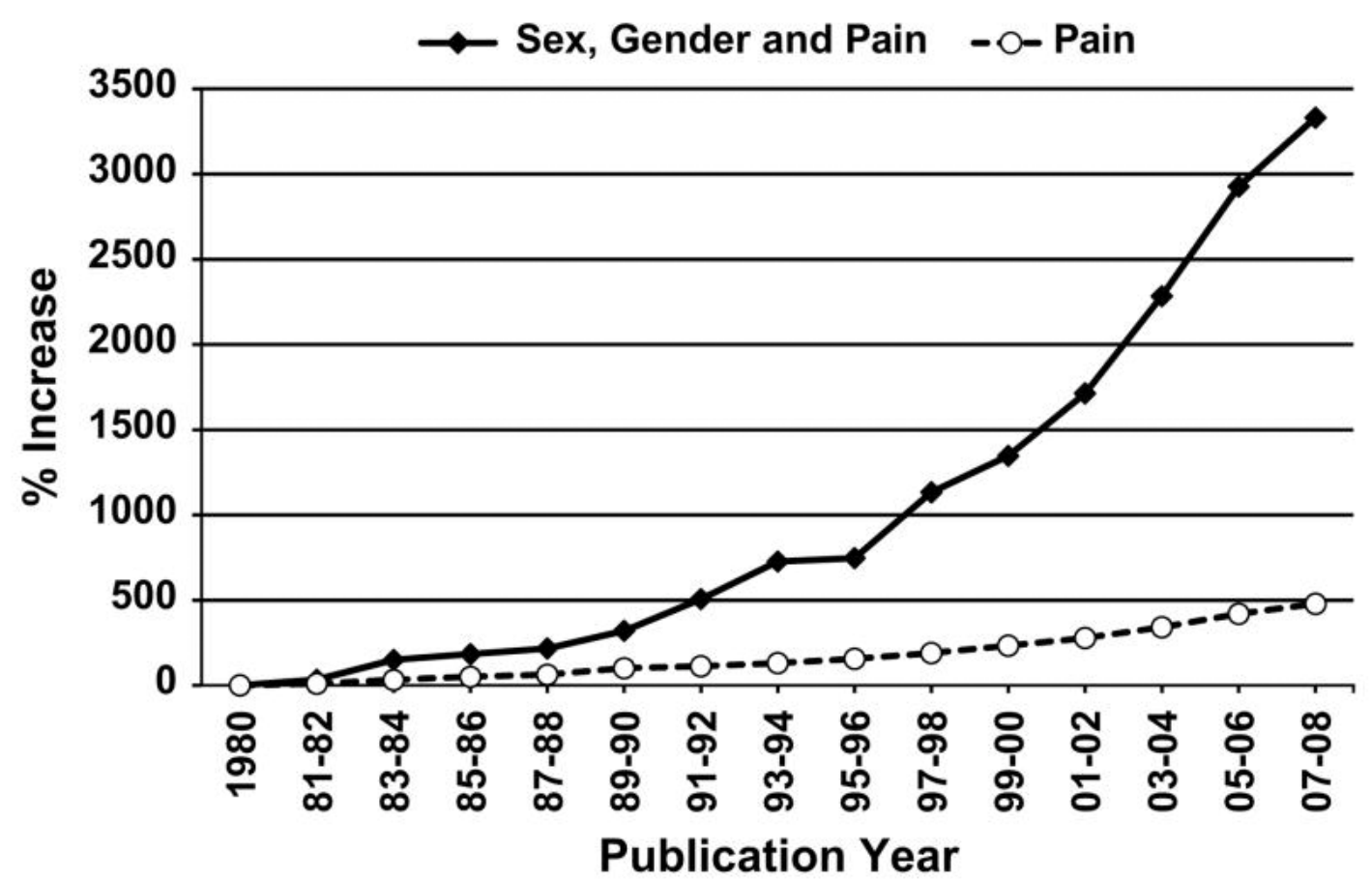

Figure 5. Average annual percentage increase in publications (obtained by PubMed searches) over each 2-year period after 1980. Reprinted from Fillingim et al., 2009 with permission from Elsevier.

\subsection{Animal studies}

A considerable number of studies on sex differences in basal nociceptive sensitivity in rodents have been made. These studies provide different and often contradictory results, which may be due to the genotype of the experimental animals, different experimental set-ups, or too small a number of subjects (Becker et al., 2005; Mogil et al., 2000; Riley et al., 1998). In the Sprague-Dawley rat, sex differences in response to acute noxious electrical and chemical pain have been reported, with females exhibiting greater pain sensitivity than males. In contrast, inconsistent findings have been reported with acute noxious thermal stimuli, and no consistent sex differences in response to persistent inflammatory pain induced by intraplantar CFA have been reported (Aloisi et al., 1994; Craft et al., 2004; Craft et al 2013; Drury and Gold, 1978; Gandelman, 1983: Gaumond et al., 2002; Mogil et al., 2000; Wang et al 2006).

Sex differences in acute pain remain after correcting for other sex-dependent factors such as body weight, suggesting that the differences may be due to gonadal hormones such as estrogen and testosterone. During periods of low estrogen, both the visceral reactivity to pain and the sensitivity of trigeminal neurons increase (Giamberardino et al., 1997; Martin et al., 2007). Ovariectomized rats that are subjected to long-term depletion of gonadal hormones exhibit a stronger response to formalin-injection, thermal stimuli, and mechanical stimuli than do intact rats (Ceccarelli et al., 2003; Ma et al., 2011; Pajot et al., 2003; Sanoja and Cervero, 2005; Stoffel et al., 2005) and estrogen replacement attenuates this response (Forman et al., 1989; Kuba et al., 2005; Ma et al., 2011; Stoffel et al., 2005). Estradiol also increases the pain threshold in ovariectomized rats in common behavioral pain tests such as hot plate- and tail flick-latencies (Craft et al., 2008; Stoffel et al., 2005). Estrogens reduce epinephrine-induced mechanical hyperalgesia (Dina et al., 2001) and, consequently, ovariectomized mice develop hyperalgesia and increased visceral sensitivity (Sanoja and Cervero, 2005). Long-term treatment with estradiol and progesterone administered through subcutaneous implants induces antinociception in response to electric foot shock in orchidectomized male rats (Liu and Gintzler, 2000). Furthermore, estradiol replacement reduces autotomy behavior after sciatic nerve injury in ovariectomized rats (Tsao et al., 1999). Given the above-mentioned 
studies, an antinociceptive effect of estrogen seems likely. On the other hand, however, male rats treated with estrogen intradermally exhibit a dose-dependent hyperalgesia in response to paw pressure (Hucho et al., 2006) and, in the castrated quail, a three-week treatment of estradiol increases pain sensitivity to a noxious thermal stimulus (hot water test) (Evrard and Balthazart, 2004b). In the hot plate test, estradiol significantly increases pain sensitivity in ovariectomized rats in some experiments (Gordon and Soliman, 1996; Ratka and Simpkins, 1991) and a reduction in tail-flick latencies after estradiol treatment has also been reported (Frye et al., 1992). Vocalization thresholds to noxious pressure stimuli increase during periods of low estrogen in the normally cycling rat (Kayser et al., 1996) and estradiol has also been shown to increase visceral nociception in response to colorectal distention in rats (Ji et al., 2005; Tang et al., 2008).

Evidently, the results regarding the effects of gonadal hormones during the normal estrous cycle and after ovariectomy remain contradictory (Craft, 2007). However, as concerns the antinociception induced by pregnancy, the results are unambiguous. As shown by Alan Gintzler already in 1980, pain thresholds in response to electric foot shock increase during pregnancy (Gintzler, 1980). The increment in nociceptive response threshold is approximately $80 \%$ (Liu and Gintzler, 2000); similar increases are seen in hormone simulated pregnancy in female as well as orchidectomized male rats, and during pseudopregnancy (Gintzler and Bohan, 1990; Liu and Gintzler, 2000).

\subsection{Human studies}

The possibility of a relationship between hormonal status and pain threshold in women was first identified by Herren 80 years ago (Herren, 1933). From that time to the present, a great many studies have been carried out in the same spirit, but with somewhat different conclusions. As a population, women show greater pain sensitivity, less tolerance to pain, and more somatization than do men (Fillingim and Maixner, 1995; Fillingim et al., 2009; Riley et al., 1998; Wiesenfeld-Hallin, 2005). Meta-analyses have concluded that sex differences are most consistently found for pressure pain and electrical stimulation but whether this is true for thermal stimuli is less well established (Mogil et al., 2000; Riley et al., 1998). A PET-study performed on healthy male and female subjects perceiving a noxious heat stimulus applied to the forearm showed a striking overlap in the pattern of cerebral activation but some differences were noted as female subjects displayed a more intense activation in the contralateral thalamus and anterior insula. In addition they perceived painful heat stimulation as more intense than male subjects (Paulson et al., 1998). Females are more sensitive than males in response to the application of glutamate to the temporomandibular joint or jaw muscles (Cairns et al., 2001) and subcutaneous injections of glutamate induce different pain and vasomotor responses in men and women (Gazerani et al., 2006). Sex differences in opioid analgesia where women generally tend to demonstrate greater analgesia than men have also been reported (for refs see Fillingim and Gear, 2004), and part of these differences has been associated with certain genetic traits (Mogil et al., 2003). However, the implications of these studies are not easily assessed. For example, in a study by Gear et al. (1996), the authors administered opiates with mixed pharmacological profiles in a model of oral pain that is not typically treated with opiates, and another study was conducted in a laboratory setting using an acute pain assay (Fillingim, 2002). The subjects were not experiencing persistent and/or severe pain, the types of pain opiates are generally prescribed for.

The most obvious sex difference with respect to pain, however, is not the difference seen in healthy subjects but the 2- to 6-fold greater prevalence of chronic pain conditions in women as compared to men (Unruh, 1996). Most idiopathic multifactorial chronic pain conditions such as irritated bowel syndrome (IBS), temporomandibular disorder (TMD), fibromyalgia-like conditions, and chronic headaches are more common in females than males. 
Other painful disorders, however, have a higher prevalence in males (e.g. cluster headache, post-traumatic headache, post-herpetic neuralgia) (Cairns, 2007). Genetic variants and polymorphisms as well as environmental factors have been shown to affect the susceptibility to different pain conditions (Diatchenko et al., 2007). Still, pain symptoms in women with IBS, TMD, and migraine fluctuate with the menstrual cycle (Houghton et al., 2002; Johannes et al., 1995; LeResche et al., 2003) and increased estrogen levels also correlate with a higher risk of chronic lower back pain (Wijnhoven et al., 2006) and temporomandibular disorders (LeResche et al., 1997). The incidence of less well-defined pain disorders such as fibromyalgia and its equivalents peaks around menopause (Pamuk and Cakir, 2005; Waxman and Zatzkis, 1986; Wolfe, 1990) and postmenopausal women have been reported to be twice as likely to experience joint pain or stiffness as premenopausal women (Szoeke et al., 2008). Furthermore, early transition to menopause (i.e. shortening the time of exposure to estrogens) has been reported to influence pain hypersensitivity in women suffering from fibromyalgia and could be related to aggravation of fibromyalgia symptoms (Martínez-Jauand et al. 2013).Taken together, these facts suggest a potential role for gonadal hormones in the pathophysiology of these disorders even though contradictory studies exist (Fillingim et al., 2009).

Many studies of healthy women show higher pain sensitivity during periods of low estrogen levels (LeResche et al., 2003; Stening et al., 2007) whereas other studies report contradictory results (Fillingim et al., 1997; Stening et al., 2012; Tsen et al., 2001). Metaanalyses of variations in pain perception across the menstrual cycle (Riley et al., 1998; Sherman and LeResche, 2006) have led to the important conclusion that the differences, if they exist at all, are small and that the different experimental set-ups make it hard to draw firm conclusions. The pregnancy-induced analgesia seen in animal experiments has also been documented in humans (Cogan and Spinnato, 1986). Using fMRI, de Leeuw et al. (2006) were able to show that the response of some brain regions to painful heat stimulation of the trigeminal nerve differed depending on the estrogen level, suggesting that sex hormones influence the activation pattern in response to painful stimuli. The changes were mostly limited to the anterior cingulate where an increase in activity was observed during periods of low estrogen. Since the anterior cingulate is involved in the affective-motivational component of pain, this localization suggests that this component is influenced by sex hormones such that it may be enhanced during periods of low estrogen levels.

With the plethora of studies on the effects of gonadal hormones on pain in mind, of which only a few have been mentioned above, it is clear that such effects do exist. It is equally clear, however, that these effects cannot easily be explained or narrowed down to one specific mechanism or outcome. The effects of estradiol, for example, may not be easily designated as either "antinociceptive" or "pronociceptive". Difficulties in isolating the effects of the respective gonadal hormones and differences in experimental design may explain some of the discrepancies in outcome. It may also be that other factors pertaining to sex indirectly affect the results from studies of nociception and pain. Differences in body constitution, hormonal effects on vasculature and mucosa, pharmacokinetics, and immune responses are a few of many such factors. The modulatory effects of each gonadal hormone on pain therefore most likely need to be specifically and qualitatively evaluated in relation to the location and intrinsic characteristics of the neurons engaged in that particular setting. To make any further advancement within the field of hormone-related pain-modulation, this fact has to be taken into account. The following parts an attempt to more specifically cover the current knowledge of mechanisms by which estrogens may affect pain transmission at the spinal and trigeminal level. 


\section{Estrogen receptor expressing neurons and their relation to nociceptive transmission}

\subsection{The characteristics of spinal ER-neurons and their relation to nociceptive transmission} at the spinal level

Early morphological studies on the distribution of estradiol-concentrating cells and the presence of ERs primarily focused on the reproductive effects of estrogen and were therefore directed at the forebrain and upper brainstem. The studies that included the lower brain stem and spinal cord only reported a small amount of estradiol-binding cells (Keefer et al., 1973; Morrell et al., 1982; Pfaff and Keiner, 1973; Pfaff, 1968) in those sites in male and female rats, which may be explained by the low sensitivity of the methods available at that time. Since the basal expression of ER $\alpha$ mRNA and protein is low in the rat spinal cord as compared to that of certain hypothalamic regions, for example (Simerly et al., 1990), applying different methods of enhancing labeling to increase sensitivity is often required. More recent studies using immunohistochemistry have shown a large amount of ER $\alpha$-expressing neurons in the superficial laminae of the spinal and trigeminal dorsal horn of the rat (Amandusson et al., 1995; Vanderhorst et al., 2005; Williams and Papka, 1996) (Fig. 4A, B). The labeling of these cells was predominantly nuclear, and they were seen throughout the spinal cord, i.e. in cervical, thoracic, lumbar and sacral segments. Spinal ER $\alpha$-containing neurons are mainly located in lamina II, with smaller numbers of cells located in lamina I, the neck of the dorsal horn, and around the central canal (lamina X). A crude estimation suggested that the total number of ER $\alpha$-expressing cells in the superficial spinal and medullary dorsal horn of the female rat is on the order of 300,000 (Amandusson et al., 1995), which indicates in turn that these spinal ER $\alpha$-neurons form one of the major ER $\alpha$-populations in the rodent brain. The adult pattern of ER $\alpha$-IR in the rat spinal cord is present by the end of the first postnatal week (Burke et al., 2000) and varies slightly with estrous stage (Williams et al., 1997). The sex differences in the distribution pattern are minor (Burke et al., 2000; Vanderhorst et al., 2005). The other known estrogen receptor, ER $\beta$, is present in laminae II-III in the spinal cord and trigeminal subnucleus caudalis, as shown in female rats (Papka et al., 2001; Shughrue et al., 1997) but the number of cells is small and the mRNA expression is low. Putative membrane ERs, such as GPR30, are also expressed in the rat spinal dorsal horn and dorsal root ganglia (Brailoiu et al., 2007; Dun et al., 2009; Takanami et al., 2010).

The fact that the neurons expressing ER $\alpha$ in the spinal cord are almost solely located in the areas of the spinal and medullary dorsal horn associated with nociceptive transmission strongly suggests that ER $\alpha$ is involved in the modulation of pain, something which is further supported by the finding that a subpopulation of these ER $\alpha$-neurons are nociceptiveresponsive (Amandusson and Blomqvist, 2010) (Fig. 6). Zhong et al. (2010) have shown that a selective $E R \alpha$-antagonist facilitates glutamatergic excitatory transmission to lamina II in response to $\mathrm{A} \delta$ - and $\mathrm{C}$-fiber stimulation in dorsal root-attached spinal cord slices from male rats. Their results suggest that endogenous estrogen may reduce glutamatergic transmission by activating ER $\alpha$ in the spinal dorsal horn, thereby inhibiting pain responses. On the other hand, a single subcutaneous injection of estradiol has also been shown to increase spinal NMDA-receptor activity and the expression of spinal NMDA-receptors in response to visceral pain in ovariectomized rats (Tang et al., 2008). A direct pain-modulating action of estrogens at the spinal level is further supported by many behavioral studies. For example, several studies demonstrate that the tail flick latency, i.e. the response to a noxious stimulus applied to the rodent's tail, which is considered to be a spinal reflex (Irwin et al., 1951), is influenced by estrogens (Frye et al., 1992; Gordon and Soliman, 1996). Albeit this effect could be due to a facilitating effect at the supraspinal level, in vivo electrophysiological experiments demonstrate that the modulation of the response takes place in the spinal cord, something that also has been shown for the estrogenic regulation of visceral sensitivity ( $\mathrm{Ji}$ et 
al., 2003; Ji et al., 2011; Tang et al., 2008). Pregnancy-induced analgesia in the rat also has an unambiguous spinal component since intrathecal but not intracerebroventricular administration of naloxone (Sander et al., 1989) attenuates it. The antinociception induced by vaginocervical stimulation in rats has also been demonstrated to be an intraspinal effect (Watkins et al., 1984), and the estrous cycle influences the amount of Fos-expressing cells in the spinal dorsal horn after vaginocervical stimulation (Ghanima et al., 2000).

\section{ER $\alpha-I R$}

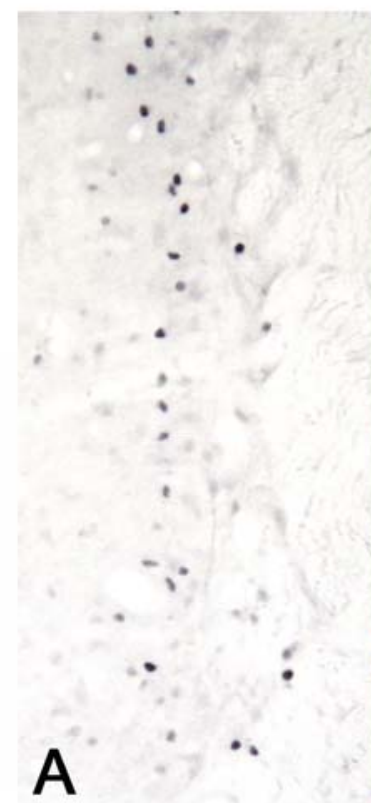

Fos-IR
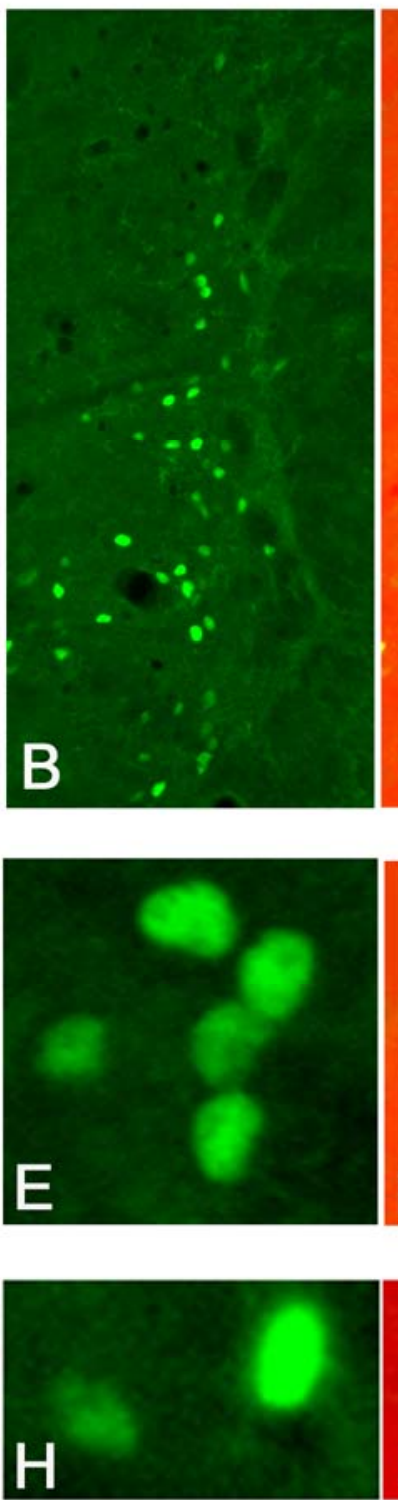

Overlay
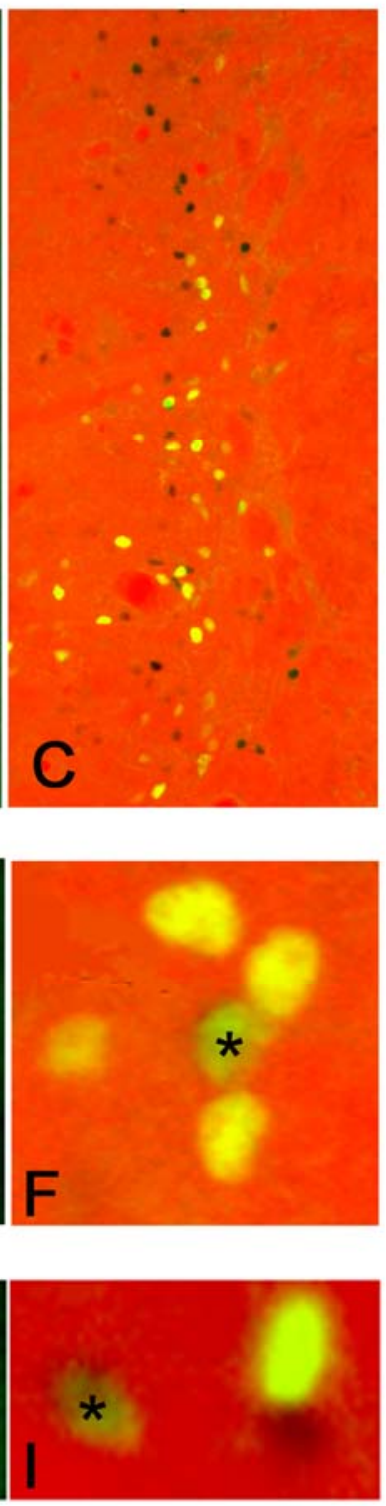

Figure 6. High-power micrographs of the superficial laminae of the medullary dorsal horn after noxious formalin injection into the lower lip. The injection induces Fos in nociceptive-responsive neurons. ER $\alpha$-immunoreactivity (dark nuclei) is shown in the left column, Fos-immunoreactivity (green fluorescentlylabeled nuclei) in the middle column, and an overlay in which the two micrographs are merged is seen in the right column. Double-labeled cells, i.e. nociceptiveresponsive cells that express ER $\alpha$, are indicated with an asterisk. Reprinted from Amandusson et al., 2010. 
In studies on mice lacking either ER $\alpha$ or ER $\beta$ (Li et al., 2009) the sex difference in basal mechanical pain threshold and carrageenan-induced inflammatory hypersensitivity was eliminated suggesting a fundamental role of these receptors in nociception in female mice. On the other hand, neither pain sensitivity in general nor the development of neuropathic pain was affected. In a later study evaluating the behavioral responses to the formalin test in these knockout mice models, a differential action of ER $\alpha$ and ER $\beta$ on pain modulation was suggested since ER $\alpha$ appeared to reduce nociceptive behavior whereas ER $\beta$ had a pronociceptive effect (Coulombe et al., 2011). Studies in ER $\beta$ knockout mice have further shown that ER $\beta$ may mediate part of the pro-nociceptive effects of estrogens in females (Spooner et al., 2007) and that it is crucial to the development of the spinal nociceptive system in this species (Fan et al., 2007). ER $\beta$ has also been implicated in the antinociceptive effect of prolonged estradiol-exposure by altering the ion channel response to capsaicin in isolated rat dorsal root ganglion sensory neurons (Xu et al., 2008). In female rats, ER $\beta$ activation attenuates the response to colorectal distention suggesting it might also be antinociceptive in this model of visceral pain (Cao et al., 2012). Recent studies have also indicated that activation of the $\mathrm{G}$ protein-coupled estrogen receptor GPR30 induces painrelated behavior and nociceptive sensitization at the spinal level in male mice (Deliu et al., 2012), and spinal administration of estradiol seems to rapidly facilitate nociceptive transmission by way of membrane estrogen receptors in the rat (Zhang et al., 2012), further adding to the complexity of estrogenic effects.

The ER $\alpha$ has been shown to be essential to estrogen-related changes in nociception (Chaban and Micevych, 2005; Evrard, 2006; Kuba et al., 2005) not only through genomic influences but most likely also in a non-genomic manner. Studies in the male quail have revealed that estradiol can modulate the response to a noxious heat stimulus very rapidly (within minutes) at the spinal level and that this effect depends on local conversion of androgens into estrogens in laminae I-II by aromatase (Evrard and Balthazart, 2004b; Evrard, 2006). There is also a significant amount of aromatase in the spinal cord of both male and female rats (Evrard, 2006; Horvath and Wikler, 1999). Local production of estrogens and neurosteroids in lamina II, which regulates genomic and non-genomic cellular mechanisms, may thus be a way by which the processing of nociceptive stimuli may be altered by steroid hormones (Evrard, 2006; Mensah-Nyagan et al., 2008; Schlichter et al., 2006). Evrard and collaborators (Evrard et al., 2000) also found that, in the spinal cord, aromatase is not controlled by testosterone suggesting that aromatase might instead be regulated by neural stimuli. Lamina II is richly innervated by glutamatergic and tachykininergic primary afferent fibers and also receives descending noradrenergic input and thus appears to be in a position to receive both afferent and descending signals that may modulate enzyme activity (Blomqvist, 2000). Indeed, a nociceptive stimulus was found to be a prerequisite for significant enkephalin release in the rat spinal cord in response to long-term administration of estradiol (Holtzman et al., 1997).

Only very few spinal ER $\alpha$-IR neurons have been shown to be projection neurons (VanderHorst et al., 1997). ER $\alpha$-IR neurons are mostly located in lamina II, suggesting that they are local interneurons. As mentioned previously, inhibitory and excitatory interneurons in lamina II strongly modulate transmission through the spinal dorsal horn and they are responsible for the setting of the "excitability level" in this area. They receive input not only from the periphery but also from other local interneurons as well as higher brain centers.

It may be concluded that the ER $\alpha$ neurons occupy a very strategic position in spinal nociceptive circuitry. However, the possibility that there are additional functions of ER $\alpha$ neurons in the superficial laminae may not be excluded. For example, there are sex differences in pruritogen-induced scratching behavior with female mice scratching more than 
male (Green et al., 2006) and some studies have shown that gonadal hormones modulate cold perception in women (Kenshalo, 1966; Soderberg et al., 2006).

\subsection{Modulation of nociceptive transmission at the level of the trigeminal system}

Several studies indicate that gonadal hormones have substantial effects on the trigeminal system in animals as well as humans. Gonadectomy increases the duration of formalininduced nociceptive behavior in the orofacial but not in the hindlimb areas in the female rat (Pajot et al., 2003), and there is a sex difference in the response to a noxious heat stimulus applied to the lip but not to the forearm (Feine et al., 1991; Lautenbacher and Rollman, 1993), suggesting that the effects of estrogens on nociception may be more pronounced in the orofacial region than in other parts of the body. In human subjects, injection of glutamate into the masseter muscle is more painful in women (Cairns et al., 2001) and the pain response to intradermal capsaicin injection to the forehead is more widely distributed in women than in men and also varies with hormonal status (Gazerani et al., 2005). There is also a higher prevalence among women of several disorders within the area innervated by the trigeminal nerve, as described previously. The trigeminal subnucleus caudalis thus provides a suitable platform for studying estrogen-dependent regulation of pain perception. Multon and collaborators (2005) showed that aromatase-knockout mice, which are totally deprived of estrogens, exhibited an increased nociceptive behavior in response to the orofacial formalin test that was normalized by preceding estradiol administration (one week of daily subcutaneous injections of $5 \mu \mathrm{g}$ estradiol). The results clearly suggest that a total lack of estrogens enhances pro-nociceptive mechanisms in the trigeminal system. This is further supported by studies showing enhanced sensitization of neurons in the trigeminal subnucleus caudalis during late proestrus and estrus when estrogen levels decline abruptly (Martin et al., 2007), and a significant dose-dependent influence of estradiol (daily subcutaneous injections of $2 \mu \mathrm{g}$ or $20 \mu \mathrm{g}$ estradiol for three days) on the encoding properties of the nociceptivespecific neurons in lamina I-II in the medullary dorsal horn of ovariectomized female rats (Tashiro et al., 2007). The neurons in laminae I-II at the subnucleus caudalis/C2-junction have been shown to play a critical role in mediating sex differences related to temporomandibular pain (Bereiter, 2001; Bereiter and Okamoto, 2011). Large amounts of ER $\alpha$-expressing neurons are present in these laminae of the trigeminal subnucleus caudalis (Amandusson et al., 1995; Vanderhorst et al., 2005) (Fig. 4) analogous to the distribution of ER $\alpha$ in the spinal dorsal horn. In the female rat, more than $40 \%$ of these cells are enkephalinergic (Amandusson et al., 1996) and some respond specifically to noxious formalin injection in the facial area (Amandusson and Blomqvist, 2010) (Fig. 6), suggesting that they may take part in pain modulation at the trigeminal level.

\subsection{Additional pain modulatory effects}

Neurons in the spinal dorsal horn that receive peripheral afferent input may not only be regulated directly by ERs in the very same neuron but also indirectly, if the neurons contributing to the afferent input contain ERs. ER $\alpha$ and ER $\beta$ are expressed in cells in the rat trigeminal ganglion (Bereiter et al., 2005) and dorsal root ganglia (DRG) and regulate sensory neuron survival during the development of the DRG in this species (Patrone et al., 1999). Estrogens profoundly increase the size of the receptive field of primary afferent nerve fibers in female rats (Bereiter and Barker, 1975; Kow and Pfaff, 1973) and rapidly attenuate nociceptive signaling in female mouse primary afferent neurons by an ER-dependent mechanism that is most likely non-genomic (Chaban et al., 2011; Chaban and Micevych, 2005). Prolonged exposure to estradiol in neuronal cultures from DRGs of female rats inhibits activation of the ion channel TRPV1, which is central to nociceptive transmission in the DRG (Xu et al., 2008) and cultured trigeminal ganglion cells from ovariectomized rats exhibit 
increased sensitivity to capsaicin (Diogenes et al., 2006). The expression of various painrelated peptides in the mouse trigeminal ganglion also varies with the estrous cycle (Puri et al., 2011; Puri et al., 2005). Estradiol modulates the expression of P2X3 receptors, known to be involved in peripheral pain signaling, in the trigeminal and dorsal root ganglia thereby affecting nociceptive transmission in the ovariectomized rat (Ma et al., 2011; Yu et al., 2011). In female rats, a subcutaneous injection of estradiol rapidly inhibits the pain behavior induced by a P2X3-receptor agonist by acting on ER $\alpha$ and GPR30 in primary afferent neurons (Lu et al., 2013) Taken all together, these findings suggest that estradiol has a prominent antinociceptive effect which is dependent on ERs in the DRG.

In addition to the proposed effects in the spinal cord and dorsal root ganglia, supraspinal modulation of nociceptive transmission also contributes to the overall effect. ERs as well as aromatase are present in many of the parts of the brain that are involved in nociceptive processing. These include the parabrachial nucleus, the nucleus of the solitary tract, the periaqueductal gray matter, the raphe nuclei, locus coeruleus and the limbic system suggesting a possibility for local estrogen synthesis and action at multiple levels. For example, ascending pathways from lumbosacral neurons terminate onto ER $\alpha$-neurons in the PAG of the female rhesus monkey (Vanderhorst et al., 2002) and ER $\alpha$-expressing neurons in the PAG of both female and male rats project to the rostral ventromedial medulla suggesting that estrogens may affect the descending pain modulating system emanating from the brain stem (Loyd and Murphy, 2008). Stimulation of the Kölliker-Fuse nucleus (A7) produces antinociception by inhibiting nociceptive neurons in the dorsal horn (Hodge et al., 1986). Estradiol given 48 hours prior to testing attenuates this antinociception (Nag and Mokha, 2004 ) in the ovariectomized rat, probably by interfering with $\alpha_{2}$-adrenoceptors. The anterior cingulate cortex is also a potential site for estrogenic influence, at least in humans (de Leeuw et al., 2006) and possibly also in rodents (Xiao et al., 2012). The expression of ER $\alpha$, and thereby the neuronal susceptibility to estrogenic influence, varies with the hormonal status in several of these pain-related areas. (Shughrue et al., 1992; Vanderhorst et al., 2005).

\section{Estrogen receptor neurons and the endogenous opioid system}

Even though it is clear that the effects of estrogens on nociception may not be entirely attributed to one single mechanism, an interaction with the endogenous opioid system seems to be of crucial importance. Analgesia during pregnancy, or its hormonal simulation, is opioid-dependent in the rat as shown by the finding that it is abolished by the opiate antagonist naloxone (Dawson-Basoa and Gintzler, 1993; Gintzler, 1980). It has been shown that this antinociception is mediated, at least to a large extent, by the activation of multiple spinal opioid systems involving $\kappa$ - and $\delta$-opioid receptors (Dawson-Basoa and Gintzler, 1997; Dawson-Basoa and Gintzler, 1998) even though peripheral as well as supraspinal mechanisms also contribute (Liu and Gintzler, 1999). Spinal dynorphin activity is central to the induction of pregnancy-induced analgesia and spinal dynorphin release is increased at least two-fold during hormone-simulated pregnancy (Gupta et al., 2001). Spinal dynorphin- and metenkephalin pathways are activated concomitantly but are subject to individual regulation (Gupta and Gintzler, 2003). As pregnancy progresses, the level of spinal met-enkephalin gradually increases throughout the spinal cord whereas the increase in dynorphin is restricted to the lumbar regions receiving pelvic afferents (Medina et al., 1993). It has been suggested that met-enkephalin therefore is of importance to the basal opioid tone and serves to facilitate spinal dynorphin activity, which is required for antinociception to occur (Gupta and Gintzler, 2003).

In non-pregnant naïve rats, opiate antagonists do not affect the basal pain threshold (Liu and Gintzler, 1999). The gonadal hormone modulation of formalin-induced pain is opioidmediated, however, most likely at a spinal level (Gaumond et al., 2007). Mu-opioid receptor 
activation in the brain in response to sustained painful stimuli is estradiol-dependent in healthy women (Smith et al., 2006) and women in a low-estradiol state demonstrate a lower capacity to activate the opioid system in response to sustained pain than men and also, consequently, display higher ratings of pain (Zubieta et al., 2002).

Hence, many studies confirm a clear interaction between estrogens and the opioid system. So, what cellular mechanisms participate in these interactions? The fact that ER $\alpha$ is coexpressed by the majority of the enkephalinergic neurons in the superficial laminae of the dorsal horn of the female rat indicates a potential site of action (Fig. 4E). In lamina II, 60-70\% of the enkephalinergic neurons contain ER $\alpha$ (Amandusson et al., 1996). The enkephalinergic neurons in lamina II are generally considered to be local circuit neurons (Fields and Basbaum, 2005; Ma et al., 1997) that exert an inhibitory effect on nociceptive transmission. They are activated by primary nociceptive and non-nociceptive afferent fibers as well as descending fibers from pain modulating regions of the brain stem (Budai et al., 1998). The levels of enkephalins in the spinal cord are directly related to the pain threshold, with increasing levels being associated with less pain sensitivity (Oshita et al., 1990). The rate of opioid peptide synthesis and release by the dorsal horn enkephalinergic neurons is thus likely to be a determining factor for the pain threshold and perceived pain intensity.

In the forebrain and hypothalamus, estradiol administration to ovariectomized animals has been shown to increase preproenkephalin mRNA expression, the concentration of endogenous opioids, and the release of endogenous opioids (Eckersell et al., 1998; Hammer et al., 1993; Priest et al., 1995; Romano et al., 1988). There are functional EREs that bind ER $\alpha$ located in the promoter region of the rat preproenkephalin gene (Zhu and Pfaff, 1995) indicating a putative direct regulatory effect of estrogens on enkephalin gene transcription. Some areas of the brain do not seem to be able to produce enkephalin in response to estrogens in spite of a morphological co-localization (Lauber et al., 1990) suggesting the possibility that regulation at the transcriptional level may be restricted and region specific. In the spinal cord, a single dose of estradiol $(50 \mu \mathrm{g} / \mathrm{kg}$;) administered subcutaneously has the ability to induce enkephalin gene expression in the ovariectomized rat (Amandusson et al., 1999). Analyses of hormonal levels from rats $4 \mathrm{~h}$ after injection revealed serum-estradiol levels that were approximately twice that of the maximum gestational level and about 16 times greater than that of naïve cycling rats (unpublished data). These levels are thus supraphysiological as has often been the case in estrogen paradigms used when studying gene expression (Micevych et al 1996). It has been shown that lower doses of estradiol may suffice to elicit gene expression (Micevych et al 1996) as well as changes in nociception (Stoffel et al 2003). However, as mentioned above, the local concentrations of estrogens in the brain may be very high due to accumulation and local synthesis and the systemic estrogen levels may therefore be of lesser importance for the interpretation of the results than previously acknowledged. The time aspect of the estrogeninduced rise in spinal enkephalin expression, which occurred within 2-4 h and lasted $>8 \mathrm{~h}$ post injection, is within the limits of a classic ER-effect. The fastest reported appearance of a protein induced by estrogen is 45 minutes (Barnea and Gorski, 1970), which makes it theoretically possible that estrogens indirectly regulate this expression by inducing a different gene in nearby neurons which could in turn affect the enkephalin gene, but the co-localization of ERs and preproenkephalin mRNA suggests that a direct effect is more likely. Considering the fact that estrogens also have the ability to stabilize mRNA, it is possible that the increase in preproenkephalin mRNA may be due to increased stability of the mRNA (Brock and Shapiro, 1983), but since studies on the induction of preproenkephalin heteronuclear RNA in the hypothalamus have indicated that estrogens have the ability to induce enkephalin gene expression (Brooks et al., 1997), the increase is most likely mainly due to this effect and not to post-translational changes. The short time span of the estrogen-induced increase of spinal enkephalin transcription, which differs from the more sustained effect seen in the 
hypothalamus (Priest et al., 1995), also indicates that changes in pain sensitivity may follow physiologically occurring fluctuations in estrogen levels.

The characteristics of the affected spinal enkephalinergic cells have not been determined. Studies of the hypothalamus have shown that the increase in preproenkephalin mRNA seen in response to a single injection of estradiol benzoate is mostly confined to steroid-responsive cells that were previously not expressing preproenkephalin mRNA, suggesting that in the hypothalamus of ovariectomized rats there are two separate preproenkephalin-populations, one in which the expression of preproenkephalin mRNA is not dependent on estrogen and another that is completely estrogen-dependent (Priest et al., 1995). There is also evidence that the expression of the rat preproenkephalin gene is differently regulated in different subsets of neurons by genomic interactions between the ERs and other steroid receptors (Pfaff et al., 1994). In a study using long-term estradiol treatment in combination with a nociceptive stimulus (formalin injection to the hind paw) in ovariectomized rats, an increase in the amount of preproenkephalin mRNA per cell was seen in the dorsal horn but no concomitant difference in the number of cells was found (Holtzman et al., 1997). A summary of possible mechanisms by which estrogens may affect the opioid system is presented in Fig 7.

The increase in spinal preproenkephalin mRNA in response to a single dose of estradiol (on average $68 \%$ ) may be compared to the $40 \%$ increase in preproenkephalin mRNA induced in the male rat dorsal horn in response to an acute noxious stimulus (Draisci and Iadarola, 1989). However, Iadarola et al (1988) have demonstrated that a 50-80\% increase in dorsal horn preproenkephalin mRNA, as seen after experimental inflammation, is not enough to yield a measurable increase in the met-enkephalin peptide content. This may be due to the fact that the constitutive synthesis of this peptide is high, rendering the endogenous protein pool large and subject to rapid turnover so that localized changes may be too marginal to be detected, at least in relation to the larger-scale changes. In rats subjected to hormone simulated pregnancy, there was no effect of long-term hormonal treatment on the basal or induced release of met-enkephalin in spinal tissue (Gupta and Gintzler, 2003). It thus remains to be shown that the estradiol-induced increase in preproenkephalin mRNA is followed by an actual increase in enkephalin peptides.

Apart from the effects on enkephalin, there are many other ways by which estrogens may affect the opioid system. For example, estrogens modulate the expression and activity of opioid receptors in pain-related brain regions, thereby influencing the antinociceptive potency of endogenous and exogenous opiates. In the parabrachial nucleus, $\mu$-opioid receptor expression fluctuates across the estrous cycle and there is a significant reduction in parabrachial $\mu$-opioid receptor expression in proestrus female rats when compared to male rats (Murphy et al., 2009). In the periaqueductal gray (PAG), a similar sex difference has been demonstrated (Loyd et al., 2008) Thus, female rats exhibit lower levels of $\mu$-opioid receptor protein in several brain regions involved in pain transmission.

In the female rat superficial dorsal horn, neurons containing ER $\alpha$ - and/or GPR30 frequently co-express opioid receptors (Liu et al., 2011) lending the possibility for estrogens to rapidly alter spinal opioid receptor dimerization and thereby opioid antinociception. This mechanism may be particularly important for dynorphin-related nociceptive signaling in the spinal cord (Gintzler and Liu, 2012b). As previously described, dynorphin is an essential component of pregnancy-induced analgesia in rats. The presence of ER $\alpha$ in dynorphinergic neurons in the dorsal horn of the rat spinal cord has been demonstrated and it has been proposed that pregnancy, by way of spinal ER $\alpha$ activation, induces dynorphin release which in turn inhibits nociceptive transmission in spinothalamic projection neurons (Gintzler et al., 2008).

Furthermore, as much as $95 \%$ of the ER-containing cells in the trigeminal subnucleus caudalis co-express the opioid receptor-like 1 receptor (ORL-1) (Flores et al., 2003), and 


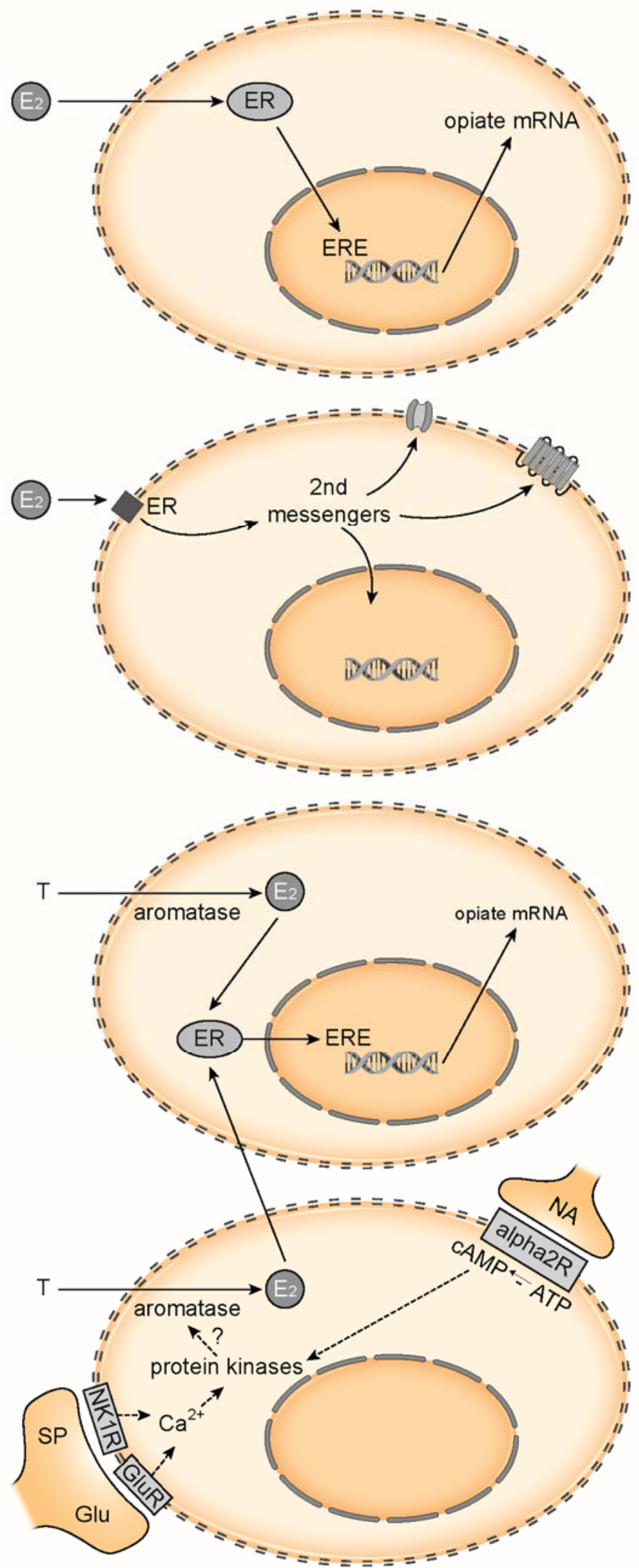

Figure 7. Different mechanisms by which estrogen-receptor neurons in the superficial dorsal horn may modulate pain processing. The top drawing shows the binding of estradiol $\left(\mathrm{E}_{2}\right)$ to intracellular estrogen receptors (ER) that may modulate mRNA transcription through interacting with genomic estrogen response elements (ERE), ERE-like sequences and different co-regulators. The second drawing shows the binding of $\mathrm{E}_{2}$ to membrane estrogen receptors affecting many intracellular pathways in turn modulating ion channels, transmembrane receptors and transcription. The bottom two drawings illustrate how testosterone (T) is converted into $E_{2}$ by aromatase present in neurons in the superficial dorsal horn. The $\mathrm{E}_{2}$ produced may then act locally in an autocrine or paracrine manner. Signaling in primary afferent or descending fibers that terminate in the superficial dorsal horn may modulate aromatase activity. SP, substance P; Glu, glutamate; NA, noradrenalin. Adapted from Blomqvist, 2000.

nociceptin/orphanin FQ, a ligand for the ORL-1, produces sex-specific nociceptive effects in the trigeminal area (Flores et al., 2001) and spinal cord (Claiborne et al., 2006). Nociceptin acts as a modulator of spinal release of enkephalin, nociceptin receptors have been located in the superficial laminae (Gupta and Gintzler, 2003), and the prepronociceptin gene contains several ER-binding sites (Xie et al., 1999). Estrogens also affect the third classic endogenous 
opioid, beta-endorphin, and its release in the hypothalamus, even though this release has not specifically been studied in relation to pain (Lapchak, 1991).

In addition to strictly opioid effects, $\alpha_{2}$-adrenoceptor-activation has been shown to produce estrogen-dependent modulation of nociception in the trigeminal area of rats (Nag and Mokha, 2006) and it is also a prerequisite for part of the antinociception seen during pregnancy (Liu and Gintzler, 1999). The antinociceptive effect of one week of daily subcutaneous injections of estradiol $(0.1 \mathrm{mg} / \mathrm{kg}$ or $1 \mathrm{mg} / \mathrm{kg})$ on Freund's complete adjuvant-induced hyperalgesia in rats also involves adrenergic mechanisms (Okuda et al., 2011). Other potential non-opioid candidates for executing estrogenic pain modulation at the spinal level include serotonin, GABA, calcitonin gene-related peptide (CGRP), cholecystokinin, and substance P (Duval et al., 1996; Ito et al., 2000; McCarthy et al., 1990; Micevych et al., 2002; Yang et al., 1998). $17 \beta$-estradiol increases the binding of muscimol to GABA-A-receptors in the female rat spinal cord and decreases the contents of substance P, CGRP and neurokinin A (Duval et al., 1996; McCarthy et al., 1991). Even though progesterone receptors have not been detected in the dorsal horn of the spinal cord (Kastrup et al., 1999), the possibility that progesterone also contributes to the effects of estrogen must be considered. Progesterone has indeed been shown to alter the nociceptive effects of estrogens (Drury and Gold, 1978; Kuba et al., 2006) at a spinal level (McCarthy et al., 1990; Medina et al., 1993; Ren et al., 2000) and to regulate nociception-related P2X3-receptor function in dorsal root ganglion neurons (Fan et al., 2011). Pregnancy-induced analgesia requires progesterone to become manifest so this analgesia is not seen in response to estrogens alone (Gintzler and Liu, 2001). A combination of estradiol and progesterone is needed to restore basal nociceptive responses to formalin injection in ovariectomized rats (Gaumond et al., 2005).

\section{Why do estrogens affect the nociceptive system?}

There is reason to believe that the diverse effects of estrogens are due to their phylogeny. Being one of the "oldest" hormones, evolved about 500 million years ago (Lange et al., 2002), and appearing in amphibians, fish, reptiles, birds and mammals, estrogens have acquired the ability to modulate many signaling pathways in the cells. Even though the basic structure is well preserved, the physiological actions are highly variable between species, affecting both the structure and organization of the tissues as well as activating and modulating their actions. Studies of the evolution of vertebrate steroid receptors suggest that an ER was, in fact, the first steroid receptor, indicating that estrogen regulation may be the most ancient mode of steroid control (Thornton, 2001). It has been hypothesized that the ER actually evolved before its estrogen ligands, working as an independent transcription factor, and that this is the explanation for the condition that estradiol, rather than any of the other steroids, may exert such a variety of effects in so many different tissues and species (Thornton, 2001). It has therefore been suggested that the effect of estrogens on pain transmission may be a by-product such that the estrogen receptor is one of many transcription factors used in sensory processing and that estrogens thereby also may modulate nociceptive transmission. The spino-parabrachial pathway previously described is likewise ancient in evolutionary terms, and it has been suggested that it is part of a homeostatic afferent network that drives the mechanisms needed to maintain the integrity of the body (Mayer et al., 2006). In that setting, a hormonal regulatory component as part of this network is highly appropriate.

The effects of gonadal hormones are important in relation to mating, pregnancy and parturition, at least in rodents. During proestrus, when estradiol levels as well as the female rat's receptivity to the male rat peak, the elevated estradiol reduces vaginocervical sensitivity so that mating is not experienced as painful, something which would otherwise compromise fertility (Ghanima et al., 2000; Komisaruk and Whipple, 1986). Yet another idea is that evolutionary pressure has favored greater general sensory acuity in females thus permitting a 
greater sensitivity and awareness of the immediate environment, resulting in greater protection in turn of the off-spring (Fillingim and Maixner, 1995).

\section{Are the effects of estrogens on pain transmission of any significance to clinical medicine?}

Before making an attempt to answer the above question, a different question must be considered: can findings regarding estrogen function in animals be translated at all to human conditions?

A comparison of ER mRNA distribution patterns in the brain suggests a similar general distribution in mammals but data from one species cannot easily be extrapolated to another (Heldring et al., 2007; Vanderhorst et al., 2009). Recent studies on primates have shown an ER $\alpha$ distribution pattern in the brain stem and spinal cord that is similar to that of rodents albeit somewhat less widespread and abundant (Vanderhorst et al., 2009). There is a high degree of DNA homology and molecular similarity between the ERs and their associated molecules, such as aromatase, between species but the physiological outcome of activation varies greatly, probably due to the fact that the binding characteristics of transcription factors may vary considerably (Odom et al., 2007). Human and rodent hormonal cycles differ significantly and it is therefore not fully possible to compare stages or cycle effects. The characteristics and temporal profiles of pregnancy-induced analgesia are, however, strikingly similar between rats and humans (Cogan and Spinnato, 1986; Gintzler and Liu, 2001). On the other hand, the outcomes of various experimental pain models as well as models of opioid analgesia are often divergent even between subpopulations of rodents (Craft, 2003; Mogil et al., 2000), indicating that there may be even more heterogeneity between animals and human subjects.

Animal experimental studies often tamper with the normal cycling conditions in one way or other, the basic set-up being the use of ovariectomized rats. Even though removing the ovaries leads to a profound decrease in hormonal levels, circulating estrogens are not completely depleted since a small yet significant amount of estrogens is produced through extragonadal conversion of androstenedione from the adrenal cortex. In addition, estrogens may be released from storage in fatty tissue for weeks following ovariectomy (Deslypere et al., 1985). These hormones are not sufficient to maintain estrous cycling but may nevertheless constitute confounding factors. Furthermore, gonadectomy disrupts the estrogenic feedback loop, resulting in increased levels of FSH and LH as well as decreased levels of prolactin (Zanisi and Martini, 1975). The obvious benefit of using ovariectomized animals is that this makes it possible to subsequently manipulate hormonal levels in a rather controlled manner. The outcome may differ radically dependent on the substitution treatment set-up chosen, however, as exemplified by Liuzzi et al (Liuzzi et al., 1999) who showed that short- and longterm treatment with estradiol had opposite effects on trkA mRNA levels in the dorsal root ganglia.

The ascending spinal sensory pathways are phylogenetically well conserved in vertebrates (Hodos and Butler, 1997) and they are quite homologous between species. Rodents do not have the distinct thalamo-cortical pain-transmitting pathways seen in primates, however, suggesting that they may not experience pain in the same way as humans (Craig, 2003a). Nevertheless, studies on sex differences in pain and analgesia have been successful regarding translational results (e.g. studies in humans and mice related to the melanocortin-1 receptor gene (Mogil et al., 2003)).

Thus far, the focus of studies on ERs in a clinical context has no doubt been the result of their importance in breast cancer development. However, emerging knowledge of the extent of ER function in many diverse tissues suggests a potentially more widespread role of ERs in disease. With the anatomical studies of the location of ERs in mind, one may speculate that 
ERs are involved not only in ER-dependent cancers but also in cardiovascular disease, osteoporosis, neurological disorders and disorders of the immune system (Nilsson et al., 2004). Mutations, deletions and polymorphisms have been reported in the ER genes and they have also, to some extent, been related to different disorders including certain pain conditions (Kang et al., 2007; Nilsson et al., 2004; Ribeiro-Dasilva et al., 2009; Roh et al., 2012; Ushiyama et al., 1998). Since the naturally occurring ligands of the ER are agonists, the actions of co-repressors are also important in the prevention of a chronically high expression of ER-inducible genes. Co-repressor dysfunction may therefore also be a pathophysiological feature. Many known co-regulators have been associated with disease in humans and these co-regulators may most likely turn out to be important therapeutic targets in the future (Lonard et al., 2007). No studies regarding pain sensitivity or other nociception-related parameters have been made on human subjects with mutations in the ER genes.

With increasing life expectancy, most women now spend a considerable part of their lives in an estrogen-deprived state. Considering the vast range of estrogenic actions throughout the body, this long-standing estrogen-deficiency may be anticipated to give rise to many pathological conditions. On the other hand, the potential adverse effects of long-time estrogen substitution must not be forgotten. Since estrogens due to their lipophilic nature have more or less free access to all cells, and the ER is a widely distributed transcription factor, estrogen replacement should obviously be made with care. Different kinds of long-term estrogen treatment have been used clinically for many years, e.g. after oophorectomy or postmenopausally. As described in this review, the relationship between estrogens and the opioid system is intricate as well as multifocal, something that perhaps should be taken into consideration when administering these hormones as well as other medications affecting gonadal hormones. For example, postmenopausal women on hormone replacement therapy (HRT) reported higher levels of orofacial pain than postmenopausal women without (Wise et al., 2000) and in a study of healthy individuals HRT was associated with lower pain thresholds and tolerances (Fillingim and Edwards, 2001). HRT as well as contraceptives are associated with a higher risk of developing temporomandibular disorders (LeResche et al., 1997) and lower back pain (Brynhildsen et al., 1998), even though it is impossible to fully determine causation. On the other hand, long-term hormonal substitution significantly reduces the content of trkA and preprotachykinin mRNA in dorsal root ganglia suggesting a decreased sensitivity to noxious stimuli (Liuzzi et al., 1999), and discontinuation of HRT has been associated with more pain or stiffness compared to placebo (Ockene et al., 2005). A positive effect of HRT was also seen in the large Women's Health Initiative study where women treated with HRT experienced a lower frequency of musculoskeletal symptoms than the placebo group (Barnabei et al., 2005, Chlebowski et al., 2013). Still, HRT does not alter symptoms or pain responses in patients with fibromyalgia (Stening et al., 2011). An occasional case report has described a distinct worsening of a chronic pain condition after treatment with an aromatase inhibitor (Nemitz et al., 2008) and aromatase inhibitor treatment in connection with breast cancer has been associated with a significant increase in the incidence of arthralgias (Burstein, 2007; Crew et al., 2007). Patients treated with the gonadotropin-releasing hormone leuprolide experience a rapid decline of estradiol and subsequent new-onset joint and muscle pain is frequent (Friedman et al., 1993).

In pharmacological studies making use of the established effects of estrogens on nociception, ERß-agonists have been shown to act as antihyperalgesics in animal models of acute inflammatory pain (Leventhal et al., 2006) as well as chronic inflammatory pain states (Gardell et al., 2008; Piu et al., 2008). A single oral dose of an ERß-agonist has proven effective, but does not seem to modify pain threshold in normal animals (Piu et al., 2008). The Erb-131, an ERß-agonist, which has been shown to rapidly alleviate pain in several animal models (Piu et al., 2008), has the ability to penetrate the CNS and a central component may 
therefore be possible. However, ERß-agonists that do not pass the blood-brain-barrier are still effective (Leventhal et al., 2006), suggesting an additional peripheral effect. It remains to be seen whether these agonists have the potential to be developed further for use in humans.

The spinal cord opiate system is in many ways more robust and efficient in male than female rodents (Gupta et al., 2007; Mitrovic et al., 2003). In male rats, intrathecal administration of morphine generates a spinal activation of $\mu$-opiate receptors that is sufficient to result in antinociception. In female rats, however, a simultaneous activation of $\kappa$-opiate receptors is required in addition to the $\mu$-opiate receptor activation in order for antinociception to occur (Liu et al., 2007). Studies on the antinociceptive mechanisms that may be recruited during pregnancy in female rats as well as humans suggest a finely tuned synergistic network of multiple spinal opioid analgesic systems, which, at first glance, may seem only beneficial. As pointed out by Gintzler and Liu (2001), however, this also has reverse implications, since a minor malfunction in one of the contributing mechanisms may result in a disproportionately large increase in pain perception. The importance of this is further underlined by the finding that sex-steroid induced analgesia is abolished by intrathecal injection of a single opioid receptor type antagonist in females whereas multiple blocking of several opioid receptors is required for abolishment in male rats (Liu and Gintzler, 2000). There is thus a sexually dimorphic recruitment of spinal opioid analgesic pathways. If this holds true for human subjects as well, this may be one reasonable explanation for the higher prevalence of chronic pain conditions in women as well as for the sex differences in antinociceptive activity of opioid agonists. In several chronic pain disorders, most notably temporomandibular disorders (TMD), the peripheral pathology is only minor and shows no relation to the pain induced. The signs and symptoms of TMD as well as the neurophysiological characteristics in experimental studies point instead to a central neural dysfunction (further elaborated on in Okamoto et al., 2003), in the case of TMD most likely emanating from the medullary dorsal horn. Although sex differences in pain sensitivity - and even the prevalence of chronic pain - may be explainable as the result of an increase in nociceptive activity, it has also been suggested that these differences arise as a result of the malfunctioning of the endogenous inhibitory pain response (Gaumond et al., 2002; Greenspan et al., 2007; Lautenbacher and Rollman, 1997). Inadequate recruitment of endogenous pain inhibitory pathways, such as the opioid system, may lead to a tendency to develop hyperalgesia and allodynia following central sensitization of dorsal horn neurons through increased NMDA and mitogen-activated protein kinase activity (Campbell and Meyer, 2006; Inturrisi, 2005; Ji et al., 2009).

As mentioned above, there is a reciprocal relationship between the opioid system and the hypothalamic-pituitary-gonadal axis such that estrogens do not only modulate opioids but the endogenous opioids, in turn, control hormonal cyclicity and ovulation. Strong pain-inhibiting responses through endogenous opioids or catecholamines may therefore be detrimental to reproduction since they impair ovulation by inhibiting LH- and FSH-secretion. Long-term pain or inflammation, profound stress and long-term opioid abuse may lead to a cessation in the normal cyclicity due to an increased opioid activity (Daniell, 2008; Genazzani et al., 1993). This might be a plausible biological background for the less robust basal expression of endogenous opioids in women.

\section{Conclusions}

The effects of estrogens on pain modulation are mediated by many different mechanisms involving multiple neuroanatomical circuits as well as diverse neurochemical systems. Estrogens, emanating from the systemic circulation or from local synthesis may, by way of slow genomic and more rapid non-genomic cellular mechanisms, regulate nociceptive circuitry at spinal and supraspinal levels, thus contributing to pain transmission and modulation. 
The literature on the effect of estrogens on pain sensitivity is without doubt contradictory. This may, at least in part, be explained by the fact that the influence of estrogen is cell- and site-specific, as has been emphasized throughout this review, and its effects may therefore differ depending on both type and location of the nociceptive stimulus, precluding generalized conclusions as to whether estrogens are anti- or pronociceptive. Further important factors in animal studies are the dose of estrogens administered, which often most likely has been supraphysiologic, and whether estrogens are given alone or in combination with progesterones. These factors, as well as the species or even strain of animals that are examined, should be considered when evaluating studies in this field. On a more global level, however, it should also be kept in mind that hormonal status and nociceptive processing both are integral components of a general interoceptive system and as such important for homeostasis (see section 3.1.). This implies that any other factor that influences homeostasis also could influence how gonadal hormones affect pain sensitivity. Quite obviously hence, in studies in humans, it is critical in which context the study was performed. The results obtained using a certain experimental set-up will always be somewhat dependent on, and reflect, the homeostatic status at that time point. Studies in healthy volunteers may therefore display a different outcome than studies in patients, in which the disease process already has resulted in homeostatic challenges and adjustments. In the same vein, it is also possible that it is a change in hormone levels, i.e. a perturbation of homeostasis, rather than the hormone level itself that is critical in relation to pain processing. Accordingly, an important factor that needs to be critically examined is at which time point after estrogen

administration/gonadectomy or during which estrous/menstrual cycle phase etc. that pain sensitivity was examined.

The role of the hormonal status for homeostasis and hence for pain processing has also implications for animal studies in which various components of estrogenic signaling are changed by genetic tools. While such work enables functional studies of the role of individual genes, and hence may provide important and necessary leaps in our understanding of estrogenic effects on pain processing, many transgenic animals have per se a perturbed homeostasis, which may confound the obtained results. The generation of animals with conditional, inducible changes in gene expression would help resolve this problem. Ideally, the findings in such well-controlled animal experiments will subsequently be tested in human subjects and hence provide clinically relevant advances in our understanding of how gonadal hormones and particularly estrogens influence pain processing.

\section{Acknowledgements}

This article is in part based on the summarizing chapter of the compilation thesis at Linköping University, "Estrogen receptor expression in relation to pain modulation and transmission: Experimental studies in rats", by Åsa Amandusson (ISBN 978-91-7393-644-6).

The Authors' work referred to in this article was supported by grants from the Swedish Research Council (\#12X-07879). 


\section{References}

Abraham, I.M., Todman, M.G., Korach, K.S., Herbison, A.E., 2004. Critical in vivo roles for classical estrogen receptors in rapid estrogen actions on intracellular signaling in mouse brain. Endocrinology 145, 3055-3061.

Ahima, R.S., Garcia, M.M., Harlan, R.E., 1992. Glucocorticoid regulation of preproenkephalin gene expression in the rat forebrain. Brain Res. Mol. Brain Res. 16, 119-127.

Al-Khater, K.M., Kerr, R., Todd, A.J., 2008. A quantitative study of spinothalamic neurons in laminae I, III, and IV in lumbar and cervical segments of the rat spinal cord. J. Comp. Neurol. 511, 1-18.

Allen, E., Doisy, E.A., 1923. An ovarian hormone: preliminary report on its localization, extraction and partial purification and action in test animals. J. Am. Med. Assoc. 81, 819-821.

Aloisi, A.M., Albonetti, M.E., Carli, G., 1994. Sex differences in the behavioural response to persistent pain in rats. Neurosci. Lett. 179, 79-82.

Altman, J., Bayer, S.A., 1984. The development of the rat spinal cord. Adv. Anat. Embryol. Cell. Biol. 85, 1-164.

Amandusson, A., Hermanson, O., Blomqvist, A., 1995. Estrogen receptor-like immunoreactivity in the medullary and spinal dorsal horn of the female rat. Neurosci. Lett. 196, 25-28.

Amandusson, A., Hermanson, O., Blomqvist, A., 1996. Colocalization of oestrogen receptor immunoreactivity and preproenkephalin mRNA expression to neurons in the superficial laminae of the spinal and medullary dorsal horn of rats. Eur. J. Neurosci. 8, $2440-2445$.

Amandusson, A., Hallbeck, M., Hallbeck, A.L., Hermanson, O., Blomqvist, A., 1999. Estrogen-induced alterations of spinal cord enkephalin gene expression. Pain 83, 243 248.

Amandusson, A., Blomqvist, A., 2010. Estrogen receptor-alpha expression in nociceptiveresponsive neurons in the medullary dorsal horn of the female rat. Eur. J. Pain 14, 245-248.

Baillien, M., Balthazart, J., 1997. A direct dopaminergic control of aromatase activity in the quail preoptic area. J. Steroid. Biochem. Mol. Biol. 63, 99-113.

Barnabei, V.M., Cochrane, B.B., Aragaki, A.K., Nygaard, I., Williams, R.S., McGovern, P.G., Young, R.L., Wells, E.C., O'Sullivan, M.J., Chen, B., Schenken, R., Johnson, S.R., 2005. Menopausal symptoms and treatment-related effects of estrogen and progestin in the Women's Health Initiative. Obstet. Gynecol. 105, 1063-1073.

Barnea, A., Gorski, J., 1970. Estrogen-induced protein. Time course of synthesis. Biochemistry 9, 1899-1904.

Becker, J.B., Arnold, A.P., Berkley, K.J., Blaustein, J.D., Eckel, L.A., Hampson, E., Herman, J.P., Marts, S., Sadee, W., Steiner, M., Taylor, J., Young, E., 2005. Strategies and methods for research on sex differences in brain and behavior. Endocrinology 146, 1650-1673. 
Bereiter, D.A., Barker, D.J., 1975. Facial receptive fields of trigeminal neurons: increased size following estrogen treatment in female rats. Neuroendocrinology 18, 115-124.

Bereiter, D.A., Hirata, H., Hu, J.W., 2000. Trigeminal subnucleus caudalis: beyond homologies with the spinal dorsal horn. Pain 88, 221-224.

Bereiter, D.A., 2001. Sex differences in brainstem neural activation after injury to the TMJ region. Cells Tissues Organs 169, 226-237.

Bereiter, D.A., Cioffi, J.L., Bereiter, D.F., 2005. Oestrogen receptor-immunoreactive neurons in the trigeminal sensory system of male and cycling female rats. Arch. Oral. Biol. 50, 971-979.

Bereiter, D.A., Okamoto, K., 2011. Neurobiology of estrogen status in deep craniofacial pain. Int. Rev. Neurobiol. 97, 251-284.

Berkley, K.J., 1997. Sex differences in pain. Behav. Brain Sci. 20, 371-380.

Bixo, M., Andersson, A., Winblad, B., Purdy, R.H., Backstrom, T., 1997. Progesterone, 5alpha-pregnane-3,20-dione and 3alpha-hydroxy-5alpha-pregnane-20-one in specific regions of the human female brain in different endocrine states. Brain Res. 764, 173 178.

Blomqvist, A., 2000. Sex hormones and pain: a new role for brain aromatase? J. Comp. Neurol. 423, 549-551.

Bodnar, R.J., 2008. Endogenous opiates and behavior: 2007. Peptides 29, 2292-2375.

Brailoiu, E., Dun, S.L., Brailoiu, G.C., Mizuo, K., Sklar, L.A., Oprea, T.I., Prossnitz, E.R., Dun, N.J., 2007. Distribution and characterization of estrogen receptor G proteincoupled receptor 30 in the rat central nervous system. J. Endocrinol. 193, 311-321.

Brannvall, K., Korhonen, L., Lindholm, D., 2002. Estrogen-receptor-dependent regulation of neural stem cell proliferation and differentiation. Mol. Cell. Neurosci. 21, 512-520.

Brock, M.L., Shapiro, D.J., 1983. Estrogen stabilizes vitellogenin mRNA against cytoplasmic degradation. Cell 34, 207-214.

Brooks, P.J., Kleopoulos, S.P., Funabashi, T., Mobbs, C.V., Pfaff, D.W., 1997. Widespread expression and estrogen regulation of PPEIA-3' nuclear RNA in the rat brain. Proc. Natl. Acad. Sci. U S A. 94, 14037-14041.

Brynhildsen, J.O., Bjors, E., Skarsgard, C., Hammar, M.L., 1998. Is hormone replacement therapy a risk factor for low back pain among postmenopausal women? Spine 23, 809813.

Budai, D., Harasawa, I., Fields, H.L., 1998. Midbrain periaqueductal gray (PAG) inhibits nociceptive inputs to sacral dorsal horn nociceptive neurons through alpha2adrenergic receptors. J. Neurophysiol. 80, 2244-2254.

Burke, K.A., Schroeder, D.M., Abel, R.A., Richardson, S.C., Bigsby, R.M., Nephew, K.P., 2000. Immunohistochemical detection of estrogen receptor alpha in male rat spinal cord during development. J. Neurosci. Res. 61, 329-337.

Burstein, H.J., 2007. Aromatase inhibitor-associated arthralgia syndrome. Breast 16, 223-234.

Cairns, B.E., Hu, J.W., Arendt-Nielsen, L., Sessle, B.J., Svensson, P., 2001. Sex-related differences in human pain and rat afferent discharge evoked by injection of glutamate into the masseter muscle. J. Neurophysiol. 86, 782-791. 
Cairns, B.E., 2007. The influence of gender and sex steroids on craniofacial nociception. Headache 47, 319-324.

Campbell, J.N., Meyer, R.A., 2006. Mechanisms of neuropathic pain. Neuron 52, 77-92.

Cao, D.Y., Ji, Y., Tang, B., Traub, R.J., 2012. Estrogen receptor beta activation is antinociceptive in a model of visceral pain in the rat. J. Pain 13, 685-694.

Ceccarelli, I., Fiorenzani, P., Massafra, C., Aloisi, A.M., 2003. Long-term ovariectomy changes formalin-induced licking in female rats: the role of estrogens. Reprod. Biol. Endocrinol. 1, 24.

Chaban, V., Li, J., McDonald, J.S., Rapkin, A., Micevych, P., 2011. Estradiol attenuates the adenosine triphosphate-induced increase of intracellular calcium through group II metabotropic glutamate receptors in rat dorsal root ganglion neurons. J. Neurosci. Res. 89, 1707-1710.

Chaban, V.V., Micevych, P.E., 2005. Estrogen receptor-alpha mediates estradiol attenuation of ATP-induced $\mathrm{Ca} 2+$ signaling in mouse dorsal root ganglion neurons. J. Neurosci. Res. 81, 31-37.

Chlebowski, R.T., Cirillo, D.J., Eaton, C.B., Stefanick, M.L., Pettinger, M., Carbone, L.D., Johnson, K.C., Simon, M.S., Woods, N.F., Wactawski-Wende, J., 2013. Estrogen alone and joint symptoms in the Women's Health Initiative randomized trial. Menopause 20, 600-608.

Christensen, B.N., Perl, E.R., 1970. Spinal neurons specifically excited by noxious or thermal stimuli: marginal zone of the dorsal horn. J. Neurophysiol. 33, 293-307.

Claiborne, J., Nag, S., Mokha, S.S., 2006. Activation of opioid receptor like-1 receptor in the spinal cord produces sex-specific antinociception in the rat: estrogen attenuates antinociception in the female, whereas testosterone is required for the expression of antinociception in the male. J. Neurosci. 26, 13048-13053.

Cogan, R., Spinnato, J.A., 1986. Pain and discomfort thresholds in late pregnancy. Pain 27, 63-68.

Colloca, L., Benedetti, F., 2005. Placebos and painkillers: is mind as real as matter? Nat. Rev. Neurosci. 6, 545-552.

Cornil, C.A., Ball, G.F., Balthazart, J., 2006. Functional significance of the rapid regulation of brain estrogen action: where do the estrogens come from? Brain Res. 1126, 2-26.

Cortright, D.N., Krause, J.E., Broom, D.C., 2007. TRP channels and pain. Biochim. Biophys. Acta. 1772, 978-988.

Coulombe, M.A., Spooner, M.F., Gaumond, I., Carrier, J.C., Marchand, S., 2011. Estrogen receptors beta and alpha have specific pro- and anti-nociceptive actions. Neuroscience $184,172-182$.

Craft, R.M., 2003. Sex differences in opioid analgesia: "from mouse to man". Clin. J. Pain 19, 175-186.

Craft, R.M., Mogil, J.S., Aloisi, A.M., 2004. Sex differences in pain and analgesia: the role of gonadal hormones. Eur. J. Pain 8, 397-411.

Craft, R.M., 2007. Modulation of pain by estrogens. Pain, 132 Suppl 1, S3-12.

Craft, R.M., Ulibarri, C., Leitl, M.D., Sumner, J.E., 2008. Dose- and time-dependent estradiol modulation of morphine antinociception in adult female rats. Eur. J. Pain 12, 472-479. 
Craft, R.M., Kandasamy, R., Davis, S.M., 2013. Sex differences in anti-allodynic, antihyperalgesic and anti-edema effects of $\Delta 9$-tetrahydrocannabinol in the rat. Pain, doi: 10.1016/j.pain.2013.05.017. [Epub ahead of print].

Craig, A.D., Bushnell, M.C., Zhang, E.T., Blomqvist, A., 1994. A thalamic nucleus specific for pain and temperature sensation. Nature 372, 770-773.

Craig, A.D., 1995. Distribution of brainstem projections from spinal lamina I neurons in the cat and the monkey. J. Comp. Neurol. 361, 225-248.

Craig, A.D., Krout, K., Andrew, D., 2001. Quantitative response characteristics of thermoreceptive and nociceptive lamina I spinothalamic neurons in the cat. J. Neurophysiol. 86, 1459-1480.

Craig, A.D., 2002. How do you feel? Interoception: the sense of the physiological condition of the body. Nat. Rev. Neurosci. 3, 655-666.

Craig, A.D., 2003a. Pain mechanisms: labeled lines versus convergence in central processing. Annu. Rev. Neurosci. 26, 1-30.

Craig, A.D., 2003b. Interoception: the sense of the physiological condition of the body. Curr. Opin. Neurobiol. 13, 500-505.

Crew, K.D., Greenlee, H., Capodice, J., Raptis, G., Brafman, L., Fuentes, D., Sierra, A., Hershman, D.L., 2007. Prevalence of joint symptoms in postmenopausal women taking aromatase inhibitors for early-stage breast cancer. J. Clin. Oncol. 25, 38773883 .

Daniell, H.W., 2008. Opioid endocrinopathy in women consuming prescribed sustainedaction opioids for control of nonmalignant pain. J. Pain 9, 28-36.

Dawson-Basoa, M., Gintzler, A.R., 1997. Involvement of spinal cord delta opiate receptors in the antinociception of gestation and its hormonal simulation. Brain Res. 757, 37-42.

Dawson-Basoa, M., Gintzler, A.R., 1998. Gestational and ovarian sex steroid antinociception: synergy between spinal kappa and delta opioid systems. Brain Res. 794, 61-67.

Dawson-Basoa, M.B., Gintzler, A.R., 1993. 17-Beta-estradiol and progesterone modulate an intrinsic opioid analgesic system. Brain Res. 601, 241-245.

de Leeuw, R., Albuquerque, R.J., Andersen, A.H., Carlson, C.R., 2006. Influence of estrogen on brain activation during stimulation with painful heat. J. Oral Maxillofac. Surg. 64, 158-166.

Deliu, E., Brailoiu, G.C., Arterburn, J.B., Oprea, T.I., Benamar, K., Dun, N.J., Brailoiu, E., 2012. Mechanisms of $\mathrm{G}$ protein-coupled estrogen receptor-mediated spinal nociception. J. Pain 13, 742-754.

Deslypere, J.P., Verdonck, L., Vermeulen, A., 1985. Fat tissue: a steroid reservoir and site of steroid metabolism. J. Clin. Endocrinol. Metab. 61, 564-570.

Diatchenko, L., Nackley, A.G., Tchivileva, I.E., Shabalina, S.A., Maixner, W., 2007. Genetic architecture of human pain perception. Trends Genet. 23, 605-613.

Dietz, S.C., Carroll, J.S., 2008. Interrogating the genome to understand oestrogen-receptormediated transcription. Expert Rev. Mol. Med. 10, e10.

Dina, O.A., Aley, K.O., Isenberg, W., Messing, R.O., Levine, J.D., 2001. Sex hormones regulate the contribution of PKCepsilon and PKA signalling in inflammatory pain in the rat. Eur. J. Neurosci. 13, 2227-2233. 
Diogenes, A., Patwardhan, A.M., Jeske, N.A., Ruparel, N.B., Goffin, V., Akopian, A.N., Hargreaves, K.M., 2006. Prolactin modulates TRPV1 in female rat trigeminal sensory neurons. J. Neurosci. 26, 8126-8136.

Draisci, G., Iadarola, M.J., 1989. Temporal analysis of increases in c-fos, preprodynorphin and preproenkephalin mRNAs in rat spinal cord. Brain Res. Mol. Brain Res. 6, 31-37.

Drury, R.A., Gold, R.M., 1978. Differential effects of ovarian hormones on reactivity to electric footshock in the rat. Physiol. Behav. 20, 187-191.

Dun, S.L., Brailoiu, G.C., Gao, X., Brailoiu, E., Arterburn, J.B., Prossnitz, E.R., Oprea, T.I., Dun, N.J., 2009. Expression of estrogen receptor GPR30 in the rat spinal cord and in autonomic and sensory ganglia. J. Neurosci. Res. 87, 1610-1619.

Duval, P., Lenoir, V., Moussaoui, S., Garret, C., Kerdelhue, B., 1996. Substance P and neurokinin A variations throughout the rat estrous cycle; comparison with ovariectomized and male rats: II. Trigeminal nucleus and cervical spinal cord. J. Neurosci. Res. 45, 610-616.

Eckersell, C.B., Popper, P., Micevych, P.E., 1998. Estrogen-induced alteration of mu-opioid receptor immunoreactivity in the medial preoptic nucleus and medial amygdala. J. Neurosci. 18, 3967-3976.

Engstrom, L., Engblom, D., Blomqvist, A., 2003. Systemic immune challenge induces preproenkephalin gene transcription in distinct autonomic structures of the rat brain. J. Comp. Neurol. 462, 450-461.

Evrard, H., Baillien, M., Foidart, A., Absil, P., Harada, N., Balthazart, J., 2000. Localization and controls of aromatase in the quail spinal cord. J. Comp. Neurol. 423, 552-564.

Evrard, H.C., Balthazart, J., 2003. Aromatase (estrogen synthase) activity in the dorsal horn of the spinal cord: functional implications. Ann. N. Y. Acad. Sci. 1007, 263-271.

Evrard, H.C., Balthazart, J., 2004a. Rapid regulation of pain by estrogens synthesized in spinal dorsal horn neurons. J. Neurosci. 24, 7225-7229.

Evrard, H.C., Balthazart, J., 2004b. Aromatization of androgens into estrogens reduces response latency to a noxious thermal stimulus in male quail. Horm. Behav. 45, 181189.

Evrard, H.C., 2006. Estrogen synthesis in the spinal dorsal horn: a new central mechanism for the hormonal regulation of pain. Am. J. Physiol. Regul. Integr. Comp. Physiol. 291, R291-299.

Fan, J., Lu, Y., Yu, L.H., Zhang, Y., Ni, X., Burnstock, G., Ma, B., 2011. Progesterone rapidly attenuates ATP-evoked transient currents in cultured rat dorsal root ganglion neurons. Pharmacology 87, 36-44.

Fan, X., Kim, H.J., Warner, M., Gustafsson, J.A., 2007. Estrogen receptor beta is essential for sprouting of nociceptive primary afferents and for morphogenesis and maintenance of the dorsal horn interneurons. Proc. Natl. Acad. Sci. U S A. 104, 13696-13701.

Feine, J.S., Bushnell, M.C., Miron, D., Duncan, G.H., 1991. Sex differences in the perception of noxious heat stimuli. Pain 44, 255-262.

Fields, H.L., Basbaum, A.I., 2005. Central nervous system mechanisms of pain modulation. In: Textbook of Pain. Vol., McMahon, S.B., Koltzenburg, M., Wall, P.D., eds., Churchill Livningstone, New York, pp. 309-329. 
Fillingim, R.B., 2002. Sex differences in analgesic responses: evidence from experimental pain models. Eur. J. Anaesthesiol. Suppl. 26, 16-24.

Fillingim, R.B., Maixner, W., 1995. Gender differences in the response to noxious stimuli. Pain Forum 4, 209-221.

Fillingim, R.B., Maixner, W., Girdler, S.S., Light, K.C., Harris, M.B., Sheps, D.S., Mason, G.A., 1997. Ischemic but not thermal pain sensitivity varies across the menstrual cycle. Psychosom. Med. 59, 512-520.

Fillingim, R.B., Edwards, R.R., 2001. The association of hormone replacement therapy with experimental pain responses in postmenopausal women. Pain 92, 229-234.

Fillingim, R.B., Gear, R.W., 2004. Sex differences in opioid analgesia: clinical and experimental findings. Eur. J. Pain 8, 413-425.

Fillingim, R.B., King, C.D., Ribeiro-Dasilva, M.C., Rahim-Williams, B., Riley, J.L., 3rd, 2009. Sex, gender, and pain: a review of recent clinical and experimental findings. J. Pain 10, 447-485.

Flores, C.A., Wang, X.M., Zhang, K.M., Mokha, S.S., 2001. Orphanin FQ produces genderspecific modulation of trigeminal nociception: behavioral and electrophysiological observations. Neuroscience 105, 489-498.

Flores, C.A., Shughrue, P., Petersen, S.L., Mokha, S.S., 2003. Sex-related differences in the distribution of opioid receptor-like 1 receptor mRNA and colocalization with estrogen receptor mRNA in neurons of the spinal trigeminal nucleus caudalis in the rat. Neuroscience 118, 769-778.

Forman, L.J., Tingle, V., Estilow, S., Cater, J., 1989. The response to analgesia testing is affected by gonadal steroids in the rat. Life Sci. 45, 447-454.

Friedman, A.J., Juneau-Norcross, M., Rein, M.S., 1993. Adverse effects of leuprolide acetate depot treatment. Fertil. Steril. 59, 448-450.

Frye, C.A., Bock, B.C., Kanarek, R.B., 1992. Hormonal milieu affects tailflick latency in female rats and may be attenuated by access to sucrose. Physiol. Behav. 52, 699-706.

Gandelman, R., 1983. Gonadal hormones and sensory function. Neurosci. Biobehav. Rev. 7, $1-17$.

Gardell, L.R., Hyldtoft, L., Del Tredici, A.L., Andersen, C.B., Fairbairn, L.C., Lund, B.W., Gustafsson, M., Brann, M.R., Olsson, R., Piu, F., 2008. Differential modulation of inflammatory pain by a selective estrogen receptor beta agonist. Eur. J. Pharmacol. 592, 158-159.

Gaub, M.P., Bellard, M., Scheuer, I., Chambon, P., Sassone-Corsi, P., 1990. Activation of the ovalbumin gene by the estrogen receptor involves the fos-jun complex. Cell 63, 12671276.

Gaumond, I., Arsenault, P., Marchand, S., 2002. The role of sex hormones on formalininduced nociceptive responses. Brain Res. 958, 139-145.

Gaumond, I., Arsenault, P., Marchand, S., 2005. Specificity of female and male sex hormones on excitatory and inhibitory phases of formalin-induced nociceptive responses. Brain Res. 1052, 105-111. 
Gaumond, I., Spooner, M.F., Marchand, S., 2007. Sex differences in opioid-mediated pain inhibitory mechanisms during the interphase in the formalin test. Neuroscience 146, 366-374.

Gazerani, P., Andersen, O.K., Arendt-Nielsen, L., 2005. A human experimental capsaicin model for trigeminal sensitization. Gender-specific differences. Pain 118, 155-163.

Gazerani, P., Wang, K., Cairns, B.E., Svensson, P., Arendt-Nielsen, L., 2006. Effects of subcutaneous administration of glutamate on pain, sensitization and vasomotor responses in healthy men and women. Pain 124, 338-348.

Gear, R.W., Miaskowski, C., Gordon, N.C., Paul, S.M., Heller, P.H., Levine, J.D., 1996. Kappa-opioids produce significantly greater analgesia in women than in men. Nat. Med. 12, 1248-1250.

Genazzani, A.R., Genazzani, A.D., Volpogni, C., Pianazzi, F., Li, G.A., Surico, N., Petraglia, F., 1993. Opioid control of gonadotrophin secretion in humans. Hum. Reprod. 8 Suppl 2, 151-153.

Ghanima, A., Bennis, M., Rampin, O., Rousseau, J.P., 2000. Influence of estrous cycle on vaginocervical sensitivity: a fos-immunohistochemical study of lumbosacral spinal cord. Brain Res. 880, 109-117.

Ghayee, H.K., Auchus, R.J., 2007. Basic concepts and recent developments in human steroid hormone biosynthesis. Rev. Endocr. Metab. Disord. 8, 289-300.

Giamberardino, M.A., Affaitati, G., Valente, R., Iezzi, S., Vecchiet, L., 1997. Changes in visceral pain reactivity as a function of estrous cycle in female rats with artificial ureteral calculosis. Brain Res. 774, 234-238.

Gintzler, A.R., 1980. Endorphin-mediated increases in pain threshold during pregnancy. Science 210, 193-195.

Gintzler, A.R., Bohan, M.C., 1990. Pain thresholds are elevated during pseudopregnancy. Brain Res. 507, 312-316.

Gintzler, A.R., Liu, N.J., 2001. The maternal spinal cord: biochemical and physiological correlates of steroid-activated antinociceptive processes. Prog. Brain Res. 133, 83-97.

Gintzler, A.R., Schnell, S.A., Gupta, D.S., Liu, N.J., Wessendorf, M.W., 2008. Relationship of spinal dynorphin neurons to delta-opioid receptors and estrogen receptor alpha: anatomical basis for ovarian sex steroid opioid antinociception. J. Pharmacol. Exp. Ther. 326, 725-731.

Gintzler, A.R., Liu, N.J., 2012a. Importance of sex to pain and its amelioration; relevance of spinal estrogens and its membrane receptors. Front. Neuroendocrinol. 33, 412-424.

Gintzler, A.R., Liu, N.J., 2012b. Importance of sex to pain and its amelioration; relevance of spinal estrogens and its membrane receptors. Front. Neuroendocrinol. 33, 412-424.

Gordon, F.T., Soliman, M.R., 1996. The effects of estradiol and progesterone on pain sensitivity and brain opioid receptors in ovariectomized rats. Horm. Behav. 30, $244-$ 250 .

Gouarderes, C., Cros, J., Quirion, R., 1985. Autoradiographic localization of mu, delta and kappa opioid receptor binding sites in rat and guinea pig spinal cord. Neuropeptides 6 , 331-342. 
Gould, E., Woolley, C.S., Frankfurt, M., McEwen, B.S., 1990. Gonadal steroids regulate dendritic spine density in hippocampal pyramidal cells in adulthood. J. Neurosci. 10, 1286-1291.

Graham, B.A., Brichta, A.M., Callister, R.J., 2007. Moving from an averaged to specific view of spinal cord pain processing circuits. J. Neurophysiol. 98, 1057-1063.

Green, A.D., Young, K.K., Lehto, S.G., Smith, S.B., Mogil, J.S., 2006. Influence of genotype, dose and sex on pruritogen-induced scratching behavior in the mouse. Pain 124, 5058.

Greenspan, J.D., Craft, R.M., LeResche, L., Arendt-Nielsen, L., Berkley, K.J., Fillingim, R.B., Gold, M.S., Holdcroft, A., Lautenbacher, S., Mayer, E.A., Mogil, J.S., Murphy, A.Z., Traub, R.J., 2007. Studying sex and gender differences in pain and analgesia: a consensus report. Pain 132 Suppl 1, S26-45.

Gruber, C.J., Tschugguel, W., Schneeberger, C., Huber, J.C., 2002. Production and actions of estrogens. N. Engl. J. Med. 346, 340-352.

Gruber, C.J., Gruber, D.M., Gruber, I.M., Wieser, F., Huber, J.C., 2004. Anatomy of the estrogen response element. Trends Endocrinol. Metab. 15, 73-78.

Gupta, D.S., Kelson, A.B., Polgar, W.E., Toll, L., Szucs, M., Gintzler, A.R., 2001. Ovarian sex steroid-dependent plasticity of nociceptin/orphanin FQ and opioid modulation of spinal dynorphin release. J. Pharmacol. Exp. Ther. 298, 1213-1220.

Gupta, D.S., Gintzler, A.R., 2003. Influence of ovarian sex steroids on spinal methionineenkephalin release: comparison with dynorphin reveals asymmetrical regulation. J. Pharmacol. Exp. Ther. 304, 738-744.

Gupta, D.S., von Gizycki, H., Gintzler, A.R., 2007. Sex-/ovarian steroid-dependent release of endomorphin 2 from spinal cord. J. Pharmacol. Exp. Ther. 321, 635-641.

Hammer, R.P., Jr., Bogic, L., Handa, R.J., 1993. Estrogenic regulation of proenkephalin mRNA expression in the ventromedial hypothalamus of the adult male rat. Brain Res. Mol. Brain Res. 19, 129-134.

Han, Z.S., Zhang, E.T., Craig, A.D., 1998. Nociceptive and thermoreceptive lamina I neurons are anatomically distinct. Nat. Neurosci. 1, 218-225.

Harlan, R.E., Shivers, B.D., Romano, G.J., Howells, R.D., Pfaff, D.W., 1987. Localization of preproenkephalin mRNA in the rat brain and spinal cord by in situ hybridization. $\mathrm{J}$. Comp. Neurol. 258, 159-184.

Heldring, N., Pike, A., Andersson, S., Matthews, J., Cheng, G., Hartman, J., Tujague, M., Strom, A., Treuter, E., Warner, M., Gustafsson, J.A., 2007. Estrogen receptors: how do they signal and what are their targets. Physiol. Rev. 87, 905-931.

Herren, R.Y., 1933. The effect of high and low female sex hormone concentrations on the two-point threshold of pain and touch and upon tactile sensitivity. J. Exp. Psychol. 16, 324-327.

Hodge, C.J., Jr., Apkarian, A.V., Stevens, R.T., 1986. Inhibition of dorsal-horn cell responses by stimulation of the Kolliker-Fuse nucleus. J. Neurosurg. 65, 825-833.

Hodos, W., Butler, A.B., 1997. Evolution of sensory pathways in vertebrates. Brain Behav. Evol. 50, 189-197. 
Hojo, Y., Murakami, G., Mukai, H., Higo, S., Hatanaka, Y., Ogiue-Ikeda, M., Ishii, H., Kimoto, T., Kawato, S., 2008. Estrogen synthesis in the brain--role in synaptic plasticity and memory. Mol. Cell Endocrinol. 290, 31-43.

Holdcroft, A., Sapsed-Byrne, S., Ma, D., Hammal, D., Forsling, M.L., 2000. Sex and oestrous cycle differences in visceromotor responses and vasopressin release in response to colonic distension in male and female rats anaesthetized with halothane. Br. J. Anaesth. 85, 907-910.

Holtzman, D.A., Brooks, P.J., Pfaff, D.W., Schwartz-Giblin, S., 1997. Preproenkephalin mRNA is regulated by an interaction between steroid hormones and nociceptive stimulation. J. Neuroendocrinol. 9, 913-922.

Hook, V., Funkelstein, L., Lu, D., Bark, S., Wegrzyn, J., Hwang, S.R., 2008. Proteases for processing proneuropeptides into peptide neurotransmitters and hormones. Annu. Rev. Pharmacol. Toxicol. 48, 393-423.

Horvath, T.L., Wikler, K.C., 1999. Aromatase in developing sensory systems of the rat brain. J. Neuroendocrinol. 11, 77-84.

Houghton, L.A., Lea, R., Jackson, N., Whorwell, P.J., 2002. The menstrual cycle affects rectal sensitivity in patients with irritable bowel syndrome but not healthy volunteers. Gut 50, 471-474.

Hucho, T.B., Dina, O.A., Kuhn, J., Levine, J.D., 2006. Estrogen controls PKCepsilondependent mechanical hyperalgesia through direct action on nociceptive neurons. Eur. J. Neurosci. 24, 527-534.

Hughes, J., Smith, T.W., Kosterlitz, H.W., Fothergill, L.A., Morgan, B.A., Morris, H.R., 1975. Identification of two related pentapeptides from the brain with potent opiate agonist activity. Nature 258, 577-580.

Hultcrantz, M., Simonoska, R., Stenberg, A.E., 2006. Estrogen and hearing: a summary of recent investigations. Acta Otolaryngol. 126, 10-14.

Iadarola, M.J., Douglass, J., Civelli, O., Naranjo, J.R., 1988. Differential activation of spinal cord dynorphin and enkephalin neurons during hyperalgesia: evidence using cDNA hybridization. Brain Res. 455, 205-212.

Inturrisi, C.E., 2005. The role of N-methyl-D-aspartate (NMDA) receptors in pain and morphine tolerance. Minerva Anestesiol. 71, 401-403.

Irwin, S., Houde, R.W., Bennett, D.R., Hendershot, L.C., Seevers, M.H., 1951. The effects of morphine methadone and meperidine on some reflex responses of spinal animals to nociceptive stimulation. J. Pharmacol. Exp. Ther. 101, 132-143.

Ito, A., Kumamoto, E., Takeda, M., Shibata, K., Sagai, H., Yoshimura, M., 2000. Mechanisms for ovariectomy-induced hyperalgesia and its relief by calcitonin: participation of 5-HT1A-like receptor on C-afferent terminals in substantia gelatinosa of the rat spinal cord. J. Neurosci. 20, 6302-6308.

Jensen, E.V., Jacobsen, H.I., 1962. Basic guides to mechanisms of estrogen receptor action. Recent Prog. Horm. Res. 18, 387-414.

Jensen, E.V., Jordan, V.C., 2003. The estrogen receptor: a model for molecular medicine. Clin. Cancer Res. 9, 1980-1989.

Ji, R.R., Gereau, R.W.t., Malcangio, M., Strichartz, G.R., 2009. MAP kinase and pain. Brain Res. Rev. 60, 135-148. 
Ji, Y., Murphy, A.Z., Traub, R.J., 2003. Estrogen modulates the visceromotor reflex and responses of spinal dorsal horn neurons to colorectal stimulation in the rat. J. Neurosci. 23, 3908-3915.

Ji, Y., Tang, B., Traub, R.J., 2005. Modulatory effects of estrogen and progesterone on colorectal hyperalgesia in the rat. Pain 117, 433-442.

Ji, Y., Tang, B., Traub, R.J., 2011. Spinal estrogen receptor alpha mediates estradiol-induced pronociception in a visceral pain model in the rat. Pain 152, 1182-1191.

Johannes, C.B., Linet, M.S., Stewart, W.F., Celentano, D.D., Lipton, R.B., Szklo, M., 1995. Relationship of headache to phase of the menstrual cycle among young women: a daily diary study. Neurology 45, 1076-1082.

Jung-Testas, I., Renoir, M., Bugnard, H., Greene, G.L., Baulieu, E.E., 1992. Demonstration of steroid hormone receptors and steroid action in primary cultures of rat glial cells. J. Steroid Biochem. Mol. Biol. 41, 621-631.

Kajander, K.C., Sahara, Y., Iadarola, M.J., Bennett, G.J., 1990. Dynorphin increases in the dorsal spinal cord in rats with a painful peripheral neuropathy. Peptides 11, 719-728.

Kakidani, H., Furutani, Y., Takahashi, H., Noda, M., Morimoto, Y., Hirose, T., Asai, M., Inayama, S., Nakanishi, S., Numa, S., 1982. Cloning and sequence analysis of cDNA for porcine beta-neo-endorphin/dynorphin precursor. Nature 298, 245-249.

Kang, S.C., Lee, D.G., Choi, J.H., Kim, S.T., Kim, Y.K., Ahn, H.J., 2007. Association between estrogen receptor polymorphism and pain susceptibility in female temporomandibular joint osteoarthritis patients. Int. J. Oral Maxillofac. Surg. 36, 391394.

Kastrup, Y., Hallbeck, M., Amandusson, A., Hirata, S., Hermanson, O., Blomqvist, A., 1999. Progesterone receptor expression in the brainstem of the female rat. Neurosci. Lett. 275, 85-88.

Kayser, V., Berkley, K.J., Keita, H., Gautron, M., Guilbaud, G., 1996. Estrous and sex variations in vocalization thresholds to hindpaw and tail pressure stimulation in the rat. Brain Res. 742, 352-354.

Keefer, D.A., Stumpf, W.E., Sar, M., 1973. Estrogen-topographical localization of estrogenconcentrating cells in the rat spinal cord following $3 \mathrm{H}$-estradiol administration. Proc. Soc. Exp. Biol. Med. 143, 414-417.

Kelly, M.J., Moss, R.L., Dudley, C.A., 1976. Differential sensitivity of preoptic-septal neurons to microelectrophoresed estrogen during the estrous cycle. Brain Res. 114, 152-157.

Kelly, M.J., Qiu, J., Ronnekleiv, O.K., 2003. Estrogen modulation of G-protein-coupled receptor activation of potassium channels in the central nervous system. Ann. N. Y. Acad. Sci. 1007, 6-16.

Kenshalo, D.R., 1966. Changes in the cool threshold associated with phases of the menstrual cycle. J. Appl. Physiol. 21, 1031-1039.

Khachaturian, H., Watson, S.J., Lewis, M.E., Coy, D., Goldstein, A., Akil, H., 1982. Dynorphin immunocytochemistry in the rat central nervous system. Peptides 3, 941954. 
Klein-Hitpass, L., Schorpp, M., Wagner, U., Ryffel, G.U., 1986. An estrogen-responsive element derived from the 5' flanking region of the Xenopus vitellogenin A2 gene functions in transfected human cells. Cell 46, 1053-1061.

Komisaruk, B.R., Whipple, B., 1986. Vaginal stimulation-produced analgesia in rats and women. Ann. N. Y. Acad. Sci. 467, 30-39.

Kow, L.M., Pfaff, D.W., 1973. Effects of estrogen treatment on the size of receptive field and response threshold of pudendal nerve in the female rat. Neuroendocrinology 13, 299313.

Kuba, T., Kemen, L.M., Quinones-Jenab, V., 2005. Estradiol administration mediates the inflammatory response to formalin in female rats. Brain Res. 1047, 119-122.

Kuba, T., Wu, H.B., Nazarian, A., Festa, E.D., Barr, G.A., Jenab, S., Inturrisi, C.E., Quinones-Jenab, V., 2006. Estradiol and progesterone differentially regulate formalininduced nociception in ovariectomized female rats. Horm. Behav. 49, 441-449.

Kuiper, G.G., Enmark, E., Pelto-Huikko, M., Nilsson, S., Gustafsson, J.A., 1996. Cloning of a novel receptor expressed in rat prostate and ovary. Proc. Natl. Acad. Sci. U S A. 93, 5925-5930.

Kuiper, G.G., Carlsson, B., Grandien, K., Enmark, E., Haggblad, J., Nilsson, S., Gustafsson, J.A., 1997. Comparison of the ligand binding specificity and transcript tissue distribution of estrogen receptors alpha and beta. Endocrinology 138, 863-870.

Lange, I.G., Hartel, A., Meyer, H.H., 2002. Evolution of oestrogen functions in vertebrates. J. Steroid. Biochem. Mol. Biol. 83, 219-226.

Lapchak, P.A., 1991. Effect of estradiol treatment on beta-endorphin content and release in the female rat hypothalamus. Brain Res. 554, 198-202.

Lauber, A.H., Romano, G.J., Mobbs, C.V., Howells, R.D., Pfaff, D.W., 1990. Estradiol induction of proenkephalin messenger RNA in hypothalamus: dose-response and relation to reproductive behavior in the female rat. Brain Res. Mol. Brain Res. 8, 4754.

Lautenbacher, S., Rollman, G.B., 1993. Sex differences in responsiveness to painful and nonpainful stimuli are dependent upon the stimulation method. Pain 53, 255-264.

Lautenbacher, S., Rollman, G.B., 1997. Possible deficiencies of pain modulation in fibromyalgia. Clin. J. Pain 13, 189-196.

LeResche, L., Saunders, K., Von Korff, M.R., Barlow, W., Dworkin, S.F., 1997. Use of exogenous hormones and risk of temporomandibular disorder pain. Pain 69, 153-160.

LeResche, L., Mancl, L., Sherman, J.J., Gandara, B., Dworkin, S.F., 2003. Changes in temporomandibular pain and other symptoms across the menstrual cycle. Pain 106, 253-261.

Leventhal, L., Brandt, M.R., Cummons, T.A., Piesla, M.J., Rogers, K.E., Harris, H.A., 2006. An estrogen receptor-beta agonist is active in models of inflammatory and chemicalinduced pain. Eur. J. Pharmacol. 553, 146-148.

Li, L., Fan, X., Warner, M., Xu, X.J., Gustafsson, J.K., Wiesenfeld-Hallin, Z., 2009. Ablation of estrogen receptor alpha or beta eliminates sex differences in mechanical pain threshold in normal and inflamed mice. Pain 143, 37-40. 
Liu, N.J., Gintzler, A.R., 1999. Gestational and ovarian sex steroid antinociception: relevance of uterine afferent and spinal alpha(2)-noradrenergic activity. Pain 83, 359-368.

Liu, N.J., Gintzler, A.R., 2000. Prolonged ovarian sex steroid treatment of male rats produces antinociception: identification of sex-based divergent analgesic mechanisms. Pain 85, 273-281.

Liu, N.J., von Gizycki, H., Gintzler, A.R., 2007. Sexually dimorphic recruitment of spinal opioid analgesic pathways by the spinal application of morphine. J. Pharmacol. Exp. Ther. 322, 654-660.

Liu, N.J., Chakrabarti, S., Schnell, S., Wessendorf, M., Gintzler, A.R., 2011. Spinal synthesis of estrogen and concomitant signaling by membrane estrogen receptors regulate spinal kappa- and mu-opioid receptor heterodimerization and female-specific spinal morphine antinociception. J. Neurosci. 31, 11836-11845.

Liuzzi, F.J., Scoville, S.A., Bufton, S.M., 1999. Long-term estrogen replacement coordinately decreases trkA and beta-PPT mRNA levels in dorsal root ganglion neurons. Exp. Neurol. 155, 260-267.

Lonard, D.M., Lanz, R.B., O'Malley, B.W., 2007. Nuclear receptor coregulators and human disease. Endocr. Rev. 28, 575-587.

Lord, J.A., Waterfield, A.A., Hughes, J., Kosterlitz, H.W., 1977. Endogenous opioid peptides: multiple agonists and receptors. Nature 267, 495-499.

Loyd, D.R., Murphy, A.Z., 2008. Androgen and estrogen (alpha) receptor localization on periaqueductal gray neurons projecting to the rostral ventromedial medulla in the male and female rat. J. Chem. Neuroanat. 36, 216-226.

Loyd, D.R., Wang, X., Murphy, A.Z., 2008. Sex differences in micro-opioid receptor expression in the rat midbrain periaqueductal gray are essential for eliciting sex differences in morphine analgesia. J. Neurosci. 28, 14007-14017.

Lu, Y., Jiang, Q., Yu, L.H., Lu, Z.Y., Meng, S.P., Su, D.F., Burnstock, G., Ma, B., 2013. 17ßEstradiol rapidly attenuates $\mathrm{P} 2 \mathrm{X} 3$ receptor-mediated peripheral pain signal transduction via ER $\alpha$ and GPR30. Endocrinology, Apr 22 [Epub ahead of print].

Ma, B., Yu, L.H., Fan, J., Cong, B., He, P., Ni, X., Burnstock, G., 2011. Estrogen modulation of peripheral pain signal transduction: involvement of $\mathrm{P} 2 \mathrm{X}(3)$ receptors. Purinergic Signal. 7, 73-83.

Ma, W., Ribeiro-da-Silva, A., De Koninck, Y., Radhakrishnan, V., Cuello, A.C., Henry, J.L., 1997. Substance P and enkephalin immunoreactivities in axonal boutons presynaptic to physiologically identified dorsal horn neurons. An ultrastructural multiple-labelling study in the cat. Neuroscience 77, 793-811.

Malan, T.P., Ossipov, M.H., Gardell, L.R., Ibrahim, M., Bian, D., Lai, J., Porreca, F., 2000. Extraterritorial neuropathic pain correlates with multisegmental elevation of spinal dynorphin in nerve-injured rats. Pain 86, 185-194.

Malyala, A., Kelly, M.J., Ronnekleiv, O.K., 2005. Estrogen modulation of hypothalamic neurons: activation of multiple signaling pathways and gene expression changes. Steroids 70, 397-406.

Martin, V.T., Lee, J., Behbehani, M.M., 2007. Sensitization of the trigeminal sensory system during different stages of the rat estrous cycle: implications for menstrual migraine. Headache 47, 552-563. 
Marvizon, J.C., Chen, W., Murphy, N., 2009. Enkephalins, dynorphins, and beta-endorphin in the rat dorsal horn: an immunofluorescence colocalization study. J. Comp. Neurol. 517, 51-68.

Matthews, J., Gustafsson, J.A., 2003. Estrogen signaling: a subtle balance between ER alpha and ER beta. Mol. Interv. 3, 281-292.

Martínez-Jauand, M., Sitges, C., Femenia, J., Cifre, I., Gonzále, S., Chialvo, D., Montoya, P. 2013. Age-of-onset of menopause is associated with enhanced painful and non-painful sensitivity in fibromyalgia. Clin. Rheumatol. Feb 16. [Epub ahead of print].

Mayer, E.A., Naliboff, B.D., Craig, A.D., 2006. Neuroimaging of the brain-gut axis: from basic understanding to treatment of functional GI disorders. Gastroenterology 131, 1925-1942.

Mazzola, L., Isnard, J., Peyron, R., Mauguiere, F., 2012. Stimulation of the human cortex and the experience of pain: Wilder Penfield's observations revisited. Brain 135, 631-640.

McCarthy, M.M., Caba, M., Komisaruk, B.R., Beyer, C., 1990. Modulation by estrogen and progesterone of the effect of muscimol on nociception in the spinal cord. Pharmacol. Biochem. Behav. 37, 123-128.

McCarthy, M.M., Coirini, H., Schumacher, M., Pfaff, D.W., McEwen, B.S., Schwartz-Giblin, S., 1991. Ovarian steroid modulation of [3H]muscimol binding in the spinal cord of the rat. Brain Res. 556, 321-323.

McEwen, B.S., 2001. Invited review: Estrogens effects on the brain: multiple sites and molecular mechanisms. J. Appl. Physiol. 91, 2785-2801.

McEwen, B.S., Akama, K.T., Spencer-Segal, J.L., Milner, T.A., Waters, E.M., 2012. Estrogen effects on the brain: actions beyond the hypothalamus via novel mechanisms. Behav. Neurosci. 126, 4-16.

Medina, V.M., Dawson-Basoa, M.E., Gintzler, A.R., 1993. 17 beta-estradiol and progesterone positively modulate spinal cord dynorphin: relevance to the analgesia of pregnancy. Neuroendocrinology 58, 310-315.

Mensah-Nyagan, A.G., Kibaly, C., Schaeffer, V., Venard, C., Meyer, L., Patte-Mensah, C., 2008. Endogenous steroid production in the spinal cord and potential involvement in neuropathic pain modulation. J. Steroid Biochem. Mol. Biol. 109, 286-293.

Micevych, P., Eckersell, C.B., Holland, K., Smith, A., 1996. Induction of CCK mRNA levels in the limbic-hypothalamic circuit: time course and site-specific effects of estrogen. J. Neurobiol. 30, 465-479.

Micevych, P., Chaban, V., Quesada, A., Sinchak, K., 2002. Oestrogen modulates cholecystokinin: opioid interactions in the nervous system. Pharmacol. Toxicol. 91, 387-397.

Micevych, P., Dominguez, R., 2009. Membrane estradiol signaling in the brain. Front. Neuroendocrinol. 30, 315-327.

Micevych, P.E., Mermelstein, P.G., 2008. Membrane estrogen receptors acting through metabotropic glutamate receptors: an emerging mechanism of estrogen action in brain. Mol. Neurobiol. 38, 66-77.

Mitrovic, I., Margeta-Mitrovic, M., Bader, S., Stoffel, M., Jan, L.Y., Basbaum, A.I., 2003. Contribution of GIRK2-mediated postsynaptic signaling to opiate and alpha 2- 
adrenergic analgesia and analgesic sex differences. Proc. Natl. Acad. Sci. U S A. 100, 271-276.

Mogil, J.S., Chesler, E.J., Wilson, S.G., Juraska, J.M., Sternberg, W.F., 2000. Sex differences in thermal nociception and morphine antinociception in rodents depend on genotype. Neurosci. Biobehav. Rev. 24, 375-389.

Mogil, J.S., Wilson, S.G., Chesler, E.J., Rankin, A.L., Nemmani, K.V., Lariviere, W.R., Groce, M.K., Wallace, M.R., Kaplan, L., Staud, R., Ness, T.J., Glover, T.L., Stankova, M., Mayorov, A., Hruby, V.J., Grisel, J.E., Fillingim, R.B., 2003. The melanocortin-1 receptor gene mediates female-specific mechanisms of analgesia in mice and humans. Proc. Natl. Acad. Sci. U S A. 100, 4867-4872.

Morrell, J.I., Wolinsky, T.D., Krieger, M.S., Pfaff, D.W., 1982. Autoradiographic identification of estradiol-concentrating cells in the spinal cord of the female rat. Exp. Brain Res. 45, 144-150.

Mosselman, S., Polman, J., Dijkema, R., 1996. ER beta: identification and characterization of a novel human estrogen receptor. FEBS Lett. 392, 49-53.

Multon, S., Pardutz, A., Mosen, J., Hua, M.T., Defays, C., Honda, S., Harada, N., Bohotin, C., Franzen, R., Schoenen, J., 2005. Lack of estrogen increases pain in the trigeminal formalin model: a behavioural and immunocytochemical study of transgenic ArKO mice. Pain 114, 257-265.

Murphy, A.Z., Suckow, S.K., Johns, M., Traub, R.J., 2009. Sex differences in the activation of the spinoparabrachial circuit by visceral pain. Physiol. Behav. 97, 205-212.

Naftolin, F., Horvath, T.L., Jakab, R.L., Leranth, C., Harada, N., Balthazart, J., 1996. Aromatase immunoreactivity in axon terminals of the vertebrate brain. An immunocytochemical study on quail, rat, monkey and human tissues. Neuroendocrinology 63, 149-155.

Nag, S., Mokha, S.S., 2004. Estrogen attenuates antinociception produced by stimulation of Kolliker-Fuse nucleus in the rat. Eur. J. Neurosci. 20, 3203-3207.

Nag, S., Mokha, S.S., 2006. Activation of alpha2-adrenoceptors in the trigeminal region produces sex-specific modulation of nociception in the rat. Neuroscience 142, 1255 1262.

Nemitz, N., Kurmann, P.T., Van Linthoudt, D., 2008. [Intensification of a diffuse chronic pain syndrome by the introduction of an aromatase inhibitor]. Praxis 97, 137-141.

Nilsson, M., Dahlman-Wright, K., Gustafsson, J.A., 2004. Nuclear receptors in disease: the oestrogen receptors. Essays Biochem. 40, 157-167.

Noda, M., Furutani, Y., Takahashi, H., Toyosato, M., Hirose, T., Inayama, S., Nakanishi, S., Numa, S., 1982. Cloning and sequence analysis of cDNA for bovine adrenal preproenkephalin. Nature 295, 202-206.

Noguchi, K., Dubner, R., Ruda, M.A., 1992. Preproenkephalin mRNA in spinal dorsal horn neurons is induced by peripheral inflammation and is co-localized with Fos and Fosrelated proteins. Neuroscience 46, 561-570.

O'Lone, R., Frith, M.C., Karlsson, E.K., Hansen, U., 2004. Genomic targets of nuclear estrogen receptors. Mol. Endocrinol. 18, 1859-1875.

Ockene, J.K., Barad, D.H., Cochrane, B.B., Larson, J.C., Gass, M., Wassertheil-Smoller, S., Manson, J.E., Barnabei, V.M., Lane, D.S., Brzyski, R.G., Rosal, M.C., Wylie-Rosett, 
J., Hays, J., 2005. Symptom experience after discontinuing use of estrogen plus progestin. J. Am. Med. Assoc. 294, 183-193.

Odom, D.T., Dowell, R.D., Jacobsen, E.S., Gordon, W., Danford, T.W., MacIsaac, K.D., Rolfe, P.A., Conboy, C.M., Gifford, D.K., Fraenkel, E., 2007. Tissue-specific transcriptional regulation has diverged significantly between human and mouse. Nat. Genet. 39, 730-732.

Okamoto, K., Hirata, H., Takeshita, S., Bereiter, D.A., 2003. Response properties of TMJ units in superficial laminae at the spinomedullary junction of female rats vary over the estrous cycle. J. Neurophysiol. 89, 1467-1477.

Okuda, K., Iwasaka, H., Hagiwara, S., Takeshima, N., Takatani, J., Uchino, T., Noguchi, T., 2011. The antinociceptive effects of estradiol on adjuvant-induced hyperalgesia in rats involve activation of adrenergic and serotonergic systems. J. Anesth. 25, 392-397.

Olszewski, J., 1950. On the anatomical and functional organization of the spinal trigeminal nucleus. J. Comp. Neurol. 92, 401-413.

Oshita, S., Yaksh, T.L., Chipkin, R., 1990. The antinociceptive effects of intrathecally administered SCH32615, an enkephalinase inhibitor in the rat. Brain Res. 515, $143-$ 148.

Ostrowsky, K., Magnin, M., Ryvlin, P., Isnard, J., Guenot, M., Mauguiere, F., 2002. Representation of pain and somatic sensation in the human insula: a study of responses to direct electrical cortical stimulation. Cereb. Cortex 12, 376-385.

Pajot, J., Ressot, C., Ngom, I., Woda, A., 2003. Gonadectomy induces site-specific differences in nociception in rats. Pain 104, 367-373.

Pamuk, O.N., Cakir, N., 2005. The variation in chronic widespread pain and other symptoms in fibromyalgia patients. The effects of menses and menopause. Clin. Exp. Rheumatol. $23,778-782$.

Papka, R.E., Storey-Workley, M., Shughrue, P.J., Merchenthaler, I., Collins, J.J., Usip, S., Saunders, P.T., Shupnik, M., 2001. Estrogen receptor-alpha and betaimmunoreactivity and mRNA in neurons of sensory and autonomic ganglia and spinal cord. Cell Tissue Res. 304, 193-214.

Patrone, C., Andersson, S., Korhonen, L., Lindholm, D., 1999. Estrogen receptor-dependent regulation of sensory neuron survival in developing dorsal root ganglion. Proc. Natl. Acad. Sci. U S A. 96, 10905-10910.

Paulson, P.E., Minoshima, S., Morrow, T.J., Casey, K.L., 1998. Gender differences in pain perception and patterns of cerebral activation during noxious heat stimulation in humans. Pain 76, 223-229.

Pennypacker, K.R., Walczak, D., Thai, L., Fannin, R., Mason, E., Douglass, J., Hong, J.S., 1993. Kainate-induced changes in opioid peptide genes and AP-1 protein expression in the rat hippocampus. J. Neurochem. 60, 204-211.

Perl, E.R., 2011. Pain mechanisms: a commentary on concepts and issues. Prog. Neurobiol. 94, 20-38.

Pert, C.B., Snyder, S.H., 1973. Opiate receptor: demonstration in nervous tissue. Science 179, 1011-1014.

Petrovic, P., Kalso, E., Petersson, K.M., Ingvar, M., 2002. Placebo and opioid analgesia-imaging a shared neuronal network. Science 295, 1737-1740. 
Peyron, R., Laurent, B., Garcia-Larrea, L., 2000. Functional imaging of brain responses to pain. A review and meta-analysis (2000). Neurophysiol. Clin. 30, 263-288.

Pfaff, D., Keiner, M., 1973. Atlas of estradiol-concentrating cells in the central nervous system of the female rat. J. Comp. Neurol. 151, 121-158.

Pfaff, D.W., 1968. Uptake of 3H-estradiol by the female rat brain. An autoradiographic study. Endocrinology 82, 1149-1155.

Pfaff, D.W., Freidin, M.M., Wu-Peng, X.S., Yin, J., Zhu, Y.S., 1994. Competition for DNA steroid response elements as a possible mechanism for neuroendocrine integration. J. Steroid Biochem. Mol. Biol. 49, 373-379.

Pfaller, K., Arvidsson, J., 1988. Central distribution of trigeminal and upper cervical primary afferents in the rat studied by anterograde transport of horseradish peroxidase conjugated to wheat germ agglutinin. J. Comp. Neurol. 268, 91-108.

Piu, F., Cheevers, C., Hyldtoft, L., Gardell, L.R., Del Tredici, A.L., Andersen, C.B., Fairbairn, L.C., Lund, B.W., Gustafsson, M., Schiffer, H.H., Donello, J.E., Olsson, R., Gil, D.W., Brann, M.R., 2008. Broad modulation of neuropathic pain states by a selective estrogen receptor beta agonist. Eur. J. Pharmacol. 590, 423-429.

Prange-Kiel, J., Rune, G.M., 2006. Direct and indirect effects of estrogen on rat hippocampus. Neuroscience 138, 765-772.

Priest, C.A., Eckersell, C.B., Micevych, P.E., 1995. Estrogen regulates preproenkephalin-A mRNA levels in the rat ventromedial nucleus: temporal and cellular aspects. Brain Res. Mol. Brain Res. 28, 251-262.

Puri, J., Bellinger, L.L., Kramer, P.R., 2011. Estrogen in cycling rats alters gene expression in the temporomandibular joint, trigeminal ganglia and trigeminal subnucleus caudalis/upper cervical cord junction. J. Cell. Physiol. 226, 3169-3180.

Puri, V., Cui, L., Liverman, C.S., Roby, K.F., Klein, R.M., Welch, K.M., Berman, N.E., 2005. Ovarian steroids regulate neuropeptides in the trigeminal ganglion. Neuropeptides 39, 409-417.

Raboisson, P., Dallel, R., Clavelou, P., Sessle, B.J., Woda, A., 1995. Effects of subcutaneous formalin on the activity of trigeminal brain stem nociceptive neurones in the rat. J. Neurophysiol. 73, 496-505.

Racine, M., Tousignant-Laflamme, Y., Kloda, L.A., Dion, D., Dupuis, G., Choiniere, M., 2012. A systematic literature review of 10 years of research on sex/gender and experimental pain perception - part 1: are there really differences between women and men? Pain 153, 602-618.

Ratka, A., Simpkins, J.W., 1991. Effects of estradiol and progesterone on the sensitivity to pain and on morphine-induced antinociception in female rats. Horm. Behav. 25, 217 228.

Ren, K., Wei, F., Dubner, R., Murphy, A., Hoffman, G.E., 2000. Progesterone attenuates persistent inflammatory hyperalgesia in female rats: involvement of spinal NMDA receptor mechanisms. Brain Res. 865, 272-277.

Revankar, C.M., Cimino, D.F., Sklar, L.A., Arterburn, J.B., Prossnitz, E.R., 2005. A transmembrane intracellular estrogen receptor mediates rapid cell signaling. Science 307, 1625-1630. 
Ribeiro-Dasilva, M.C., Peres Line, S.R., Leme Godoy dos Santos, M.C., Arthuri, M.T., Hou, W., Fillingim, R.B., Rizzatti Barbosa, C.M., 2009. Estrogen receptor-alpha polymorphisms and predisposition to TMJ disorder. J. Pain 10, 527-533.

Riley, J.L., 3rd, Robinson, M.E., Wise, E.A., Myers, C.D., Fillingim, R.B., 1998. Sex differences in the perception of noxious experimental stimuli: a meta-analysis. Pain 74, 181-187.

Roh, H.L., Lee, J.S., Suh, K.T., Kim, J.I., Lee, H.S., Goh, T.S., Park, S.H., 2012. Association Between Estrogen Receptor Gene Polymorphism and Back Pain Intensity in Female Patients With Degenerative Lumbar Spondylolisthesis. J. Spinal Disord. Tech. Jun 1 [Epub ahead of print]

Romano, G.J., Harlan, R.E., Shivers, B.D., Howells, R.D., Pfaff, D.W., 1988. Estrogen increases proenkephalin messenger ribonucleic acid levels in the ventromedial hypothalamus of the rat. Mol. Endocrinol. 2, 1320-1328.

Sander, H.W., Kream, R.M., Gintzler, A.R., 1989. Spinal dynorphin involvement in the analgesia of pregnancy: effects of intrathecal dynorphin antisera. Eur. J. Pharmacol. $159,205-209$.

Sanoja, R., Cervero, F., 2005. Estrogen-dependent abdominal hyperalgesia induced by ovariectomy in adult mice: a model of functional abdominal pain. Pain 118, 243-253.

Schlichter, R., Keller, A.F., De Roo, M., Breton, J.D., Inquimbert, P., Poisbeau, P., 2006. Fast nongenomic effects of steroids on synaptic transmission and role of endogenous neurosteroids in spinal pain pathways. J. Mol. Neurosci. 28, 33-51.

Schmahmann, J.D., Leifer, D., 1992. Parietal pseudothalamic pain syndrome. Clinical features and anatomic correlates. Arch. Neurol. 49, 1032-1037.

Sherman, J.J., LeResche, L., 2006. Does experimental pain response vary across the menstrual cycle? A methodological review. Am. J. Physiol. Regul. Integr. Comp. Physiol. 291, R245-256.

Shiau, A.K., Barstad, D., Loria, P.M., Cheng, L., Kushner, P.J., Agard, D.A., Greene, G.L., 1998. The structural basis of estrogen receptor/coactivator recognition and the antagonism of this interaction by tamoxifen. Cell 95, 927-937.

Shughrue, P.J., Bushnell, C.D., Dorsa, D.M., 1992. Estrogen receptor messenger ribonucleic acid in female rat brain during the estrous cycle: a comparison with ovariectomized females and intact males. Endocrinology 131, 381-388.

Shughrue, P.J., Lane, M.V., Merchenthaler, I., 1997. Comparative distribution of estrogen receptor-alpha and -beta mRNA in the rat central nervous system. J. Comp. Neurol. $388,507-525$.

Shughrue, P.J., Scrimo, P.J., Merchenthaler, I., 1998. Evidence for the colocalization of estrogen receptor-beta mRNA and estrogen receptor-alpha immunoreactivity in neurons of the rat forebrain. Endocrinology 139, 5267-5270.

Shughrue, P.J., Merchenthaler, I., 2001. Distribution of estrogen receptor beta immunoreactivity in the rat central nervous system. J. Comp. Neurol. 436, 64-81.

Simantov, R., Kuhar, M.J., Uhl, G.R., Snyder, S.H., 1977. Opioid peptide enkephalin: immunohistochemical mapping in rat central nervous system. Proc. Natl. Acad. Sci. U S A 74, 2167-2171. 
Simerly, R.B., Chang, C., Muramatsu, M., Swanson, L.W., 1990. Distribution of androgen and estrogen receptor mRNA-containing cells in the rat brain: an in situ hybridization study. J. Comp. Neurol. 294, 76-95.

Smith, Y.R., Stohler, C.S., Nichols, T.E., Bueller, J.A., Koeppe, R.A., Zubieta, J.K., 2006. Pronociceptive and antinociceptive effects of estradiol through endogenous opioid neurotransmission in women. J. Neurosci. 26, 5777-5785.

Soderberg, K., Sundstrom Poromaa, I., Nyberg, S., Backstrom, T., Nordh, E., 2006. Psychophysically determined thresholds for thermal perception and pain perception in healthy women across the menstrual cycle. Clin. J. Pain 22, 610-616.

Spike, R.C., Puskar, Z., Andrew, D., Todd, A.J., 2003. A quantitative and morphological study of projection neurons in lamina I of the rat lumbar spinal cord. Eur. J. Neurosci. $18,2433-2448$.

Spooner, M.F., Robichaud, P., Carrier, J.C., Marchand, S., 2007. Endogenous pain modulation during the formalin test in estrogen receptor beta knockout mice. Neuroscience 150, 675-680.

Stening, K., Eriksson, O., Wahren, L., Berg, G., Hammar, M., Blomqvist, A., 2007. Pain sensations to the cold pressor test in normally menstruating women: comparison with men and relation to menstrual phase and serum sex steroid levels. Am. J. Physiol. Regul. Integr. Comp. Physiol. 293, R1711-1716.

Stening, K.D., Eriksson, O., Henriksson, K.G., Brynhildsen, J., Lindh-Astrand, L., Berg, G., Hammar, M., Amandusson, A., Blomqvist, A., 2011. Hormonal replacement therapy does not affect self-estimated pain or experimental pain responses in post-menopausal women suffering from fibromyalgia: a double-blind, randomized, placebo-controlled trial. Rheumatology 50, 544-551.

Stening, K.D., Berg, G., Hammar, M., Voster, H., Eriksson, O., Amandusson, A., Blomqvist, A., 2012. Influence of estrogen levels on thermal perception, pain thresholds, and pain tolerance: studies on women undergoing in vitro fertilization. J. Pain 13, 459-466.

Stoffel, E.C., Ulibarri, C.M., Folk, J.E., Rice, K.C., Craft, R.M., 2005. Gonadal hormone modulation of mu, kappa, and delta opioid antinociception in male and female rats. J. Pain 6, 261-274.

Stumpf, W.E., Sar, M., 1976. Steroid hormone target sites in the brain: the differential distribution of estrogin, progestin, androgen and glucocorticosteroid. J. Steroid Biochem. 7, 1163-1170.

Sugiura, Y., Lee, C.L., Perl, E.R., 1986. Central projections of identified, unmyelinated (C) afferent fibers innervating mammalian skin. Science 234, 358-361.

Szego, C.M., Davis, J.S., 1967. Adenosine 3',5'-monophosphate in rat uterus: acute elevation by estrogen. Proc. Natl. Acad. Sci. U S A 58, 1711-1718.

Szoeke, C.E., Cicuttini, F.M., Guthrie, J.R., Dennerstein, L., 2008. The relationship of reports of aches and joint pains to the menopausal transition: a longitudinal study. Climacteric $11,55-62$.

Takanami, K., Sakamoto, H., Matsuda, K., Hosokawa, K., Nishi, M., Prossnitz, E.R., Kawata, M., 2010. Expression of $\mathrm{G}$ protein-coupled receptor 30 in the spinal somatosensory system. Brain Res. 1310, 17-28. 
Tang, B., Ji, Y., Traub, R.J., 2008. Estrogen alters spinal NMDA receptor activity via a PKA signaling pathway in a visceral pain model in the rat. Pain 137, 540-549.

Tashiro, A., Okamoto, K., Milam, S.B., Bereiter, D.A., 2007. Differential effects of estradiol on encoding properties of TMJ units in laminae I and $\mathrm{V}$ at the spinomedullary junction in female rats. J. Neurophysiol. 98, 3242-3253.

Terenius, L., 1973. Characteristics of the "receptor" for narcotic analgesics in synaptic plasma membrane fraction from rat brain. Acta Pharmacol. Toxicol. 33, 377-384.

Tetel, M.J., Pfaff, D.W., 2010. Contributions of estrogen receptor-alpha and estrogen receptor-ss to the regulation of behavior. Biochim. Biophys. Acta 1800, 1084-1089.

Thomas, P., Pang, Y., Filardo, E.J., Dong, J., 2005. Identity of an estrogen membrane receptor coupled to a $\mathrm{G}$ protein in human breast cancer cells. Endocrinology 146, 624-632.

Thornton, J.W., 2001. Evolution of vertebrate steroid receptors from an ancestral estrogen receptor by ligand exploitation and serial genome expansions. Proc. Natl. Acad. Sci. U S A. 98, 5671-5676.

Toft, D., Gorski, J., 1966. A receptor molecule for estrogens: isolation from the rat uterus and preliminary characterization. Proc. Natl. Acad. Sci. U S A. 55, 1574-1581.

Toran-Allerand, C.D., Guan, X., MacLusky, N.J., Horvath, T.L., Diano, S., Singh, M., Connolly, E.S., Jr., Nethrapalli, I.S., Tinnikov, A.A., 2002. ER-X: a novel, plasma membrane-associated, putative estrogen receptor that is regulated during development and after ischemic brain injury. J. Neurosci. 22, 8391-8401.

Treede, R.D., Kenshalo, D.R., Gracely, R.H., Jones, A.K., 1999. The cortical representation of pain. Pain 79, 105-111.

Tsao, C.M., Ho, C.M., Tsai, S.K., Lee, T.Y., 1999. Effects of estrogen on autotomy in normal and ovariectomized rats. Pharmacology 59, 142-148.

Tsen, L.C., Natale, M., Datta, S., Eappen, S., 2001. Can estrogen influence the response to noxious stimuli? J. Clin. Anesth. 13, 118-121.

Uht, R.M., Anderson, C.M., Webb, P., Kushner, P.J., 1997. Transcriptional activities of estrogen and glucocorticoid receptors are functionally integrated at the AP-1 response element. Endocrinology 138, 2900-2908.

Unruh, A.M., 1996. Gender variations in clinical pain experience. Pain 65, 123-167.

Ushiyama, T., Ueyama, H., Inoue, K., Nishioka, J., Ohkubo, I., Hukuda, S., 1998. Estrogen receptor gene polymorphism and generalized osteoarthritis. J. Rheumatol. 25, 134137.

Walker, V.R., Korach, K.S., 2004. Estrogen receptor knockout mice as a model for endocrine research. ILAR J. 45, 455-461.

Walter, P., Green, S., Greene, G., Krust, A., Bornert, J.M., Jeltsch, J.M., Staub, A., Jensen, E., Scrace, G., Waterfield, M., et al., 1985. Cloning of the human estrogen receptor cDNA. Proc. Natl. Acad. Sci. U S A. 82, 7889-7893.

VanderHorst, V.G., Meijer, E., Schasfoort, F.C., Van Leeuwen, F.W., Holstege, G., 1997. Estrogen receptor-immunoreactive neurons in the lumbosacral cord projecting to the periaqueductal gray in the ovariectomized female cat. Neurosci Lett. 236, 25-28.

Vanderhorst, V.G., Terasawa, E., Ralston, H.J., 3rd, 2002. Estrogen receptor-alpha immunoreactive neurons in the ventrolateral periaqueductal gray receive 
monosynaptic input from the lumbosacral cord in the rhesus monkey. J. Comp. Neurol. 443, 27-42.

Vanderhorst, V.G., Gustafsson, J.A., Ulfhake, B., 2005. Estrogen receptor-alpha and -beta immunoreactive neurons in the brainstem and spinal cord of male and female mice: relationships to monoaminergic, cholinergic, and spinal projection systems. J. Comp. Neurol. 488, 152-179.

Vanderhorst, V.G., Terasawa, E., Ralston, H.J., 3rd, 2009. Estrogen receptor-alpha immunoreactive neurons in the brainstem and spinal cord of the female rhesus monkey: species-specific characteristics. Neuroscience 158, 798-810.

Wang, L., Andersson, S., Warner, M., Gustafsson, J.A., 2003. Estrogen receptor (ER)beta knockout mice reveal a role for ERbeta in migration of cortical neurons in the developing brain. Proc. Natl. Acad. Sci. U S A 100, 703-708.

Wang, Z., Gardell, L.R., Ossipov, M.H., Vanderah, T.W., Brennan, M.B., Hochgeschwender, U., Hruby, V.J., Malan, T.P., Jr., Lai, J., Porreca, F., 2001. Pronociceptive actions of dynorphin maintain chronic neuropathic pain. J. Neurosci. 21, 1779-1786.

Wang, X., Traub, R.J., Murphy, A.Z., 2006. Persistent pain model reveals sex difference in morphine potency. Am. J. Physiol. Regul. Integr. Comp. Physiol. 291, R300-306.

Watkins, L.R., Faris, P.L., Komisaruk, B.R., Mayer, D.J., 1984. Dorsolateral funiculus and intraspinal pathways mediate vaginal stimulation-induced suppression of nociceptive responding in rats. Brain Res. 294, 59-65.

Waxman, J., Zatzkis, S.M., 1986. Fibromyalgia and menopause. Examination of the relationship. Postgrad. Med. 80, 165-167, 170-161.

Weber, E., Roth, K.A., Barchas, J.D., 1982. Immunohistochemical distribution of alpha-neoendorphin/dynorphin neuronal systems in rat brain: evidence for colocalization. Proc. Natl. Acad. Sci. U S A. 79, 3062-3066.

Weidner, C., Schmelz, M., Schmidt, R., Hansson, B., Handwerker, H.O., Torebjork, H.E., 1999. Functional attributes discriminating mechano-insensitive and mechanoresponsive C nociceptors in human skin. J. Neurosci. 19, 10184-10190.

Wiesenfeld-Hallin, Z., 2005. Sex differences in pain perception. Gend. Med. 2, 137-145.

Wijnhoven, H.A., de Vet, H.C., Smit, H.A., Picavet, H.S., 2006. Hormonal and reproductive factors are associated with chronic low back pain and chronic upper extremity pain in women--the MORGEN study. Spine 31, 1496-1502.

Williams, S.J., Papka, R.E., 1996. Estrogen receptor-immunoreactive neurons are present in the female rat lumbosacral spinal cord. J. Neurosci. Res. 46, 492-501.

Williams, S.J., Chung, K., Om, A.S., Papka, R.E., 1997. Cytosolic estrogen receptor concentrations in the lumbosacral spinal cord fluctuate during the estrous cycle. Life Sci. 61, 2551-2559.

Willis, W.D., Jr., 1988. Anatomy and physiology of descending control of nociceptive responses of dorsal horn neurons: comprehensive review. Prog. Brain Res. 77, 1-29.

Wise, E.A., Riley, J.L., 3rd, Robinson, M.E., 2000. Clinical pain perception and hormone replacement therapy in postmenopausal women experiencing orofacial pain. Clin. J. Pain 16, 121-126. 
Wise, P.M., Dubal, D.B., Wilson, M.E., Rau, S.W., Bottner, M., 2001. Minireview: neuroprotective effects of estrogen-new insights into mechanisms of action. Endocrinology 142, 969-973.

Wolfe, F., 1990. Fibromyalgia. Rheum. Dis. Clin. North. Am. 16, 681-698.

Woolley, C.S., McEwen, B.S., 1992. Estradiol mediates fluctuation in hippocampal synapse density during the estrous cycle in the adult rat. J. Neurosci. 12, 2549-2554.

Wu, H.H., Wilcox, G.L., McLoon, S.C., 1994. Implantation of AtT-20 or genetically modified AtT-20/hENK cells in mouse spinal cord induced antinociception and opioid tolerance. J. Neurosci. 14, 4806-4814.

Xiao, X., Yang, Y., Zhang, Y., Zhang, X.M., Zhao, Z.Q., Zhang, Y.Q., 2012. Estrogen in the anterior cingulate cortex contributes to pain-related aversion. Cereb. Cortex, Jul 24 [Epub ahead of print].

Xie, G.X., Ito, E., Maruyama, K., Suzuki, Y., Sugano, S., Sharma, M., Pietruck, C., Palmer, P.P., 1999. The promoter region of human prepro-nociceptin gene and its regulation by cyclic AMP and steroid hormones. Gene 238, 427-436.

Xu, S., Cheng, Y., Keast, J.R., Osborne, P.B., 2008. 17beta-estradiol activates estrogen receptor beta-signalling and inhibits transient receptor potential vanilloid receptor 1 activation by capsaicin in adult rat nociceptor neurons. Endocrinology 149, 55405548 .

Yang, Y., Ozawa, H., Lu, H., Yuri, K., Hayashi, S., Nihonyanagi, K., Kawata, M., 1998. Immunocytochemical analysis of sex differences in calcitonin gene-related peptide in the rat dorsal root ganglion, with special reference to estrogen and its receptor. Brain Res. 791, 35-42.

Yu, L.H., Li, N., Liu, C.Y., Ma, B., 2011. Estrogen altered facial mechanical pain threshold and trigeminal P2X3 receptor expression. Neuroendocrinol. Lett. 32, 811-815.

Zanisi, M., Martini, L., 1975. Differential effects of castration on LH and FSH secretion in male and female rats. Acta Endocrinol. 78, 683-688.

Zhang, Y., Lü, N., Zhao, Z.Q., Zhang, Y.Q., 2012. Involvement of estrogen in rapid pain modulation in the rat spinal cord. Neurochem. Res. 37, 2697-2705.

Zhong, Y.Q., Li, K.C., Zhang, X., 2010. Potentiation of excitatory transmission in substantia gelatinosa neurons of rat spinal cord by inhibition of estrogen receptor alpha. Mol. Pain 6, 92.

Zhu, Y.S., Pfaff, D.W., 1995. DNA binding of hypothalamic nuclear proteins on estrogen response element and preproenkephalin promoter: modification by estrogen. Neuroendocrinology 62, 454-466.

Zhu, Y.S., Yen, P.M., Chin, W.W., Pfaff, D.W., 1996. Estrogen and thyroid hormone interaction on regulation of gene expression. Proc. Natl. Acad. Sci. U S A. 93, 1258712592.

Zubieta, J.K., Smith, Y.R., Bueller, J.A., Xu, Y., Kilbourn, M.R., Jewett, D.M., Meyer, C.R., Koeppe, R.A., Stohler, C.S., 2002. mu-opioid receptor-mediated antinociceptive responses differ in men and women. J. Neurosci. 22, 5100-5107. 